\title{
Progressive Failure Modeling of Laminates incorporating Material and Geometric Nonlinearities
}

\author{
Shiladitya Basu* and Anthony M. Waas ${ }^{\dagger}$ \\ University of Michigan, Ann Arbor, Michigan, 48109 \\ Damodar R. Ambur ${ }^{\ddagger}$ \\ NASA Glenn Research Center, Cleveland, $\mathrm{OH} 44135$
}

April 17, 2006

$47^{\text {th }}$ Structures, Structural Dynamics, and Materials Conference, $1^{\text {st }}-4^{\text {th }}$ May, 2006, Newport, RI

\begin{abstract}
A mechanism-based progressive failure analyses (PFA) approach is developed for fiber reinforced composite laminates. Each ply of the laminate is modeled as a nonlinear elastic degrading lamina in a state of plane stress according to Schapery theory $\left(\mathrm{ST}^{\mathbf{1}}\right)$. In ST, the lamina degradation in the transverse directions, is characterized through laboratory scale experiments. In the fiber direction, elastic behavior prevails until fiber tensile failure (in tension) or the attainment of a limit load instability in compression. The phenomenon of fiber microbuckling, which is associated with the limit load instability, is explicitly accounted for by allowing the fiber rotation at a material point to be a variable in the problem. The latter is motivated by experimental and numerical simulations that show that local fiber rotations in conjunction with a continuously degrading matrix are responsible for the onset of fiber microbuckling leading to kink banding. These features are built into a user defined material subroutine that is implemented through the commercial finite element (FE) software ABAQUS. Thus, the present model disbands the notion of a fixed compressive strength of a lamina. Instead the mechanics of the failure process is used to provide the in-situ compression strength of a material point in a lamina, the latter being dictated strongly by the current local stress state, the current state of the lamina transverse material properties and the local fiber rotation. The inputs to the present work are laboratory scale, coupon level test data that provide information on the lamina transverse property degradation (i.e. appropriate, measured, strain-stress relations of the lamina transverse properties), the elastic lamina orthotropic properties and the geometry of the structural panel. The validity of the approach advocated is demonstrated through numerical simulations of the response of a composite structural panel that is loaded to complete failure. A centrally notched 90-ply unstiffened stitched panel subjected to axial compression is selected for study. The predictions of the simulations are compared against experimental data.
\end{abstract}

\section{Introduction}

A large body of literature devoted to progressive failure analysis (PFA) of composite laminated structures is now present. Many of the PFA schemes have relied on the phenomenological approach of defining strength criteria for a single lamina when subjected to different single component stress states. These methods define

\footnotetext{
*Research Associate, University of Michigan, member, AIAA.

${ }^{\dagger}$ Professor, author to whom all correspondence should be addressed. (dcw@umich.edu, Tel:734-764-8227, Fax:734-763-0578), Associate Fellow, AIAA.

${ }^{\ddagger}$ Chief, Structures Division, NASA Glenn Research Center, Cleveland, OH. Associate Fellow, AIAA.

Copyright (c) 2006 by Anthony M. Waas. Published by the American Institute of Aeronautics and Astronautics, Inc. with permission.
} 
the onset of failure through specific indices that are expressed as functions of the current stress state. When any of these indices exceeds a predefined critical value, the material at that point is said to have failed ${ }^{2,3}$. When a material point has failed, for subsequent loading, it is assumed to have a reduced stiffness that is predetermined in an empirical manner. Depending on the type of failure (for instance, fiber breaking and/or matrix cracking due to tension along the fibers, fiber kink-banding due to compression along the fibers, fiber/matrix debonding due to in-plane shear), different elastic moduli are set to zero. In addition, linear elastic material behavior is assumed throughout the analysis. Furthermore, these approaches lack an appropriate definition of the material state beyond first failure. In a laminated composite plate, the stiffness at a material point is determined by the current local stress state and the local 'state' of the material. The local stress state, in general, is multi-axial and a material point at the current state may have accumulated damage, dictated by the loading history. Thus, 'strength' at a material point is influenced to a great extent by the current stress and strain state and is predicated on the mechanism of failure. Schemes that abruptly change material properties and rely on a linear elastic analysis may be unable to realistically account for features associated with the mechanisms of failure. Recently, an improved PFA scheme that still relies on strength indices but indirectly accounts for fiber misalignment has been introduced in Pinho et $\mathrm{al}^{4}$. This PFA methodology is an improvement over the previous LaC02 criteria developed by Dávila et $\mathrm{al}^{5}$.

For progressive failure modeling, a framework that accounts for the continued degradation of the material is needed. Schapery ${ }^{1}$ introduced a thermodynamically based theory (referred to as ST) that uses internal state variables (ISVs) to analyze damage evolution in composite laminates. These ISVs are related to mechanical aspects of damage mechanisms. The ISVs are related to the energy required for the evolution of the damaged states. Different damage mechanisms can have distinct ISVs to track the damage evolution. For instance, matrix microcracking can be expressed via one ISV, while transverse cracking can be represented by another ISV ${ }^{6}$. The evolution of these ISVs with global loading is determined at each material point and as functions of load history through the satisfaction of a thermodynamic criterion (an evolution equation), throughout the loading history. Various experimental ${ }^{7}$ and analytical ${ }^{8}$ studies show that the maximum load $^{2}$ sustained by a lamina in the axial direction $\left(\sigma_{11}^{c r}\right)$, in compression, depends greatly on the presence of the other in-plane stress components such as $\sigma_{22}$ and $\tau_{12}$. Experimental, analytical and micromechanical studies show that the main physical event occurring during kinking is the rotation of fibers within a degrading matrix. The rotation of fibers gives rise to high localized shear strains which drives the shear degradation of the local matrix. The shear degradation in turn drives the rotation of the fibers creating a positive feedback loop. The simultaneous presence of both these phenomena results in a limit load situation for a lamina under axial compression. This limiting load, which is dictated by the local stress state and the state of the transverse lamina properties, can be relieved (increased) by the presence of other stress components or, in certain cases, can be elevated (reduced). The present approach captures these two phenomena in a numerical setting and is able to reproduce the broad micromechanical observations associated with compressive failure at a macro-level (lamina level, instead of at the individual fiber/matrix level). A structural panel configuration, for which a set of laboratory data is available, is studied using the present PFA approach. A set of thick (90-ply), stitched unstiffened laminated panels with angled central notches subjected to axial compression loading are analyzed. Centrally notched panels (CNPs), with rectangular notches at the center are cut from a master laminate. The notches act as stress concentrators and create a high stress zone ahead of the notch tips, making it easier to observe damage initiation and progression. The use of a stitched laminate eliminates delamination among adjacent plies of a multidirectional laminate making it possible to isolate matrix dominated failure events in an uncomplicated manner. For these CNPs, experimental results and related PFA modeling has been reported earlier ${ }^{9}$. The shorter sides of the CNPs are subjected to remote uniaxial displacement control compression loading (Figure 1). The longer sides are placed in anti-buckling guides to prevent premature global buckling. Figure 1 shows the loading scheme and boundary conditions. Global load-deflection data and damage initiation and progression data obtained from laboratory experiments are used to validate the present PFA approach.

The main objective of the present paper is to validate a new PFA approach ${ }^{10,11}$ for composite laminates that is based on capturing features associated with failure mechanisms and embedding these in a numerical scheme that can model the laminate as a collection of degrading lamina. The selected examples account for material degradation in a progressive and nonlinear manner (CNP) which dominate the response of structures that are loaded in compression. 


\section{Progressive Failure Analysis using Schapery Theory (ST)}

\section{A. Elements of the PFA approach}

\section{Non-linear Constitutive Formulation}

Schapery ${ }^{12}$ developed nonlinear elastic constitutive relations for an orthotropic lamina using a work potential approach which accounted for the effect of microdamage. The lamina stress-strain relations are,

$$
\begin{aligned}
\sigma_{11} & =Q_{11} \epsilon_{11}+Q_{12} \epsilon_{22} \\
\sigma_{22} & =Q_{12} \epsilon_{11}+Q_{22} \epsilon_{22} \\
\tau_{12} & =Q_{66} \gamma_{12}
\end{aligned}
$$

where,

$$
\begin{array}{rll}
Q_{11}=\frac{E_{11}}{1-\nu_{12} \nu_{21}} & ; \quad & Q_{22}=\frac{E_{22}}{1-\nu_{12} \nu_{21}} \\
Q_{12}=\nu_{12} Q_{22} & ; \quad & Q_{66}=G_{12} \\
\nu_{21}= & \frac{\nu_{12} E_{22}}{E_{11}}
\end{array}
$$

In the existing literature on damage mechanics as applied to continuous fiber laminated composite materials, the effect of damage is incorporated through the change in transverse Young's modulus $E_{22}$ and in plane shear modulus $G_{12}$. For instance, Sun and Chen ${ }^{13}$ proposed a one parameter plastic potential in conjunction with orthotropic incremental plasticity theory to study the evolution of $E_{22}$ and $G_{12}$ in tension. Schapery ${ }^{6}$, used ST to study the evolution of $E_{22}$ and $G_{12}$. These previous studies were not concerned with

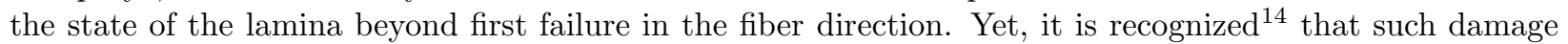
is dominant for compression loaded composite structures. Lamina level coupon tests in tension have shown that fiber direction modulus, $E_{11}$ and Poisson's ratio, $\nu_{12}$ can be assumed to be independent of microdamage that influence $E_{22}$ and $G_{12}{ }^{15}$. This situation is also true for compression until the onset of kinking (the axial compression load reaches a maximum limit load at which a kink band starts to form, for example, as shown in Lee and Waas $^{16}$ ). During kink band formation and propagation, it is likely that microdamage mechanisms do influence $E_{11}, \nu_{12}, E_{22}$ and $G_{12}$. Subsequent to kink banding, other failure mechanisms such as delamination can occur. These mechanisms are not accounted for here, but have received attention recently in the context of $\mathrm{PFA}^{17}$.

\section{Elements of Schapery Theory}

In Schapery and Sicking, ${ }^{6}$ ISVs are used to incorporate inelastic behavior in the material response. Earlier, Schapery ${ }^{1}$, introduced a more general thermodynamic framework to study materials that undergo damage. In these developments, the total work done, $W_{T}$, in a mechanical process is composed of the inelastic work, $W_{s}$ and the work of deformation $W$.

$$
W_{T}=W+W_{s}
$$

The irrecoverable portion of total energy $\left(W_{s}\right)$ can be determined from the material stress-strain response as shown in Figure 2. $I S V$ s are described through $S_{i}$ 's. Each $S_{i}$ is associated with a particular damage mechanism. To satisfy the path independence of total work, these $I S V$ s have to satisfy the following relation,

$$
f_{i}=\frac{\partial W_{s}}{\partial S_{i}}
$$

The left hand side of Eq. (4) is referred to as the thermodynamic force related to the $i^{\text {th }} I S V$. If the $i^{\text {th }}$ driving force, which is the available thermodynamic force, given by Eq. (5), exceeds $\frac{\partial W_{s}}{\partial S_{i}}$, then the material undergoes a structural change that is associated with $S_{i}$.

$$
f_{i} \equiv-\frac{\partial W}{\partial S_{i}}
$$

Stated another way,

$$
\dot{S}_{i}>0
$$


The overdot represents temporal derivative. However, as pointed out by Schapery ${ }^{1}$, it is to be noted that if the available thermodynamic force, $\left(-\frac{\partial W}{\partial S_{i}}\right)$ is less than the required thermodynamic force $\left(\frac{\partial W_{s}}{\partial S_{i}}\right)$ then,

$$
\dot{S}_{i}=0
$$

Furthermore, $S_{i}$ need not change continuously with the loading.

Schapery and Sicking ${ }^{6}$ considered two $I S V$ s. They were the energies associated with matrix microcracks $(S)$ and of the transverse intra-ply cracks $\left(S_{c}\right)$, respectively. Inelastic work is described as,

$$
W_{s}=S+S_{c}
$$

In the present work, the effect of only one ISV is entertained and is denoted by $S$. This ISV represents the irrecoverable energy content due to the accumulation of damage and is characterized through laboratory experiments that bring out transverse property degradation.

The ISV affects the moduli $E_{22}$ and $G_{12}$ through Eq. (9)

$$
\begin{aligned}
& E_{22}=E_{22_{0}} e_{s}(S) \\
& G_{12}=G_{12_{0}} g_{s}(S)
\end{aligned}
$$

Here, $E_{22_{0}}$ and $G_{12_{0}}$ are transverse and shear moduli of the virgin material, i.e., at zero strain and zero damage; $e_{s}(S)$ and $g_{s}(S)$ are functions relating these two moduli to $S$. The functions $e_{s}$ and $g_{s}$ are expressed as polynomial functions of $S$.

The strain energy density (or work of deformation) can be written as

$$
W=\frac{1}{2}\left(Q_{11} \epsilon_{11}^{2}+Q_{22} \epsilon_{22}^{2}\right)+Q_{12} \epsilon_{11} \epsilon_{22}+Q_{66} \frac{\gamma_{12}^{2}}{2}
$$

To incorporate geometric nonlinearities, Green's strains and the second Piola Kirchoff stresses need to be used in the expression for $W$. For small strains, Eq. (10), would contain only the first order terms in the strain-displacement relations. Schapery and Sicking ${ }^{6}$ have shown that material non-linearities as incorporated in Eq. (10) are still significant for fiber reinforced composites even when inclusion of geometric nonlinearities are not called for ${ }^{18}$.

Using Eqs (1)-(5), the evolution equations for $S$ is as follows,

$$
\frac{\epsilon_{11}^{2}}{2} \frac{\partial Q_{11}}{\partial S}+\frac{\epsilon_{22}^{2}}{2} \frac{\partial Q_{22}}{\partial S}+\epsilon_{11} \epsilon_{22} \frac{\partial Q_{12}}{\partial S}+\frac{\gamma_{12}^{2}}{2} \frac{\partial G_{12}}{\partial S}=-1
$$

For most materials $\nu_{12} \nu_{21} \ll 1$ which implies that, the $Q_{i j}$ 's can be replaced by $E_{i j}$ 's. In the present work, it is assumed that the fiber direction stiffnesses are unaffected by $S$. Thus, the term containing $Q_{11}$ in Eq. (11) can be neglected. It is also assumed that $\nu_{12}$ changes with $S$ such that $\nu_{12} E_{22}$ remains constant during loading. The implications of this assumption are two fold. Firstly, it allows for a change in $\nu_{12}$ with damage accumulation in the lamina. Secondly, it makes it possible to uncouple $\epsilon_{11}$ from the microcracking damage accumulation. If $\epsilon_{11}$ is present in the evolution equation (Eq. (11)), then microcracking damage becomes a direct function of the longitudinal strain, which is an improper representation of the underlying mechanism. Eq. (11) can be reduced to,

$$
\frac{\epsilon_{22}^{2}}{2} \frac{\partial E_{22}}{\partial S}+\frac{\gamma_{12}^{2}}{2} \frac{\partial G_{12}}{\partial S}=-1
$$

For an inelastic process, the entropy production rate is non-negative. Hence,

$$
\dot{S} \geq 0
$$

Physically, $\dot{S}$ is non-negative because healing (or reversible damage) is not allowed for in the damage mechanism considered.

From experiments ${ }^{6}$, it has been observed that for small strains, $\mathrm{S}$ behaves as $\epsilon^{3}$. This is based on the fact that the moduli are constant for small strains. Thus to express the moduli, $E_{22}$ and $G_{12}$ in terms of a polynomial of $S$, a reduced variable $S_{r}$ can be used,

$$
S_{r} \equiv S^{1 / 3}
$$


The evolution equation for $S_{r}$ now becomes,

$$
\frac{\epsilon_{22}^{2}}{2} \frac{\partial E_{22}}{\partial S_{r}}+\frac{\gamma_{12}^{2}}{2} \frac{\partial G_{12}}{\partial S_{r}}=-3 S_{r}^{2}
$$

It should be noted that it is possible to include other softening damage mechanisms such as local fibermatrix debonding and shear banding through $S$ as has been discussed by Schapery ${ }^{1}$.

During laboratory experiments the accumulated damage in a lamina reaches a saturation limit and the specimen fails in a catastrophic manner. The corresponding value of $S_{r}$, obtained from the resultant stressstrain plot, is denoted by $S_{r}^{*}$. For the purpose of extending the analyses beyond $S_{r}^{*}$, it is imperative for the design of a PFA to ensure a stable numerical scheme beyond this point.

\section{Fiber rotation under axial compression}

Results from previous experimental, analytical and numerical studies have shown that the main feature of laminate failure under predominantly compression loading is fiber kinking. The presence of initial fiber misalignment in a lamina that experiences compression along the fibers gives rise to local shear strain in the matrix adjacent to the misaligned fibers. These shear strains accelerate degradation of the local matrix shear stiffness. Imperfect fiber systems are prone to rotate under axial compression. That is, the fibers within a lamina that are subjected to axial compression have the propensity to change their alignment. This change is dictated by the local multiaxial stress state and the local shear stiffness of the matrix. As the local shear strains degrade the matrix shear stiffness, the resistance to fiber rotation diminishes and slowly the fiber rotation begins to build up which in turn creates more local imperfection and local shear strain. Thus a positive feedback loop is established between these two competing events. A point is reached when the in-situ shear stiffness is not sufficient to prevent the additional fiber rotation. This point usually coincides with the limit load in an axial compression material response curve. Beyond this point, the matrix is unable to resist any fiber rotation and the fibers rotate aligning themselves in localized deformed bands, commonly described as kink bands.

Consider a fiber reinforced lamina under a generalized load state as indicated in Figure 3(a). A band of misaligned fibers is shown sandwiched between two regions where the fibers are nominally straight and aligned. This equilibrium configuration is conceptualized from images of kink bands captured experimentally (Figure 3(b)). In these real kink bands, there is a conical region where fiber bending is dominant and this regions is sandwiched between the regions where there is dominant shearing (inside the band) and the far-field aligned region where there is uniform deformation (Figure 3(c)). Owing to the fiber bending dominant region, the kink band boundary inclination $\left(\beta+\beta_{0}\right)$ has the flexibility of changing during the loading, i.e., there is continuous exchange of material between the fiber bending dominant region and the shearing dominant region. In the idealization presented here, the fiber bending dominant region is disregarded and the shearing dominant region is assumed to be held in equilibrium between the two nominally aligned regions.

A reference frame $x-y$ can be defined such that the $x$-direction is parallel to the nominal fiber direction in the lamina and the $y$-direction is normal to it. In subsequent discussions, the $x-y$ reference frame will be termed as the 'global' frame. The misaligned band of fibers, in the current configuration, is defined through two angles, $\hat{\phi}=\phi+\phi_{0}$ and $\hat{\beta}=\beta+\beta_{0}$. The angles $\left(\phi_{0}, \beta_{0}\right)$ are constants and the angles $\phi$ and $\beta$ are variables that may change as a function of current far-field stress state. The reference frame, 1-2, is defined in the unstressed initial configuration of the misaligned lamina. Fibers inside the misaligned band are parallel to the ' 1 ' direction in the initial state. A current reference frame $1^{\prime}-2^{\prime}$ is defined where ' 1 '' is always parallel to the current fiber direction inside the band, thus the 1-axis rotates to 1 '-axis during loading. The ' 2 ' and ' 2 ', directions are always orthogonal to the ' 1 ' and ' 1 '' directions respectively. The 1-2 frame will be defined as the 'local' frame and the $1^{\prime}-2^{\prime}$ system will be termed the instantaneous frame. Initially, when the matrix retains most of its in-situ shear stiffness, the 1-2 and $1^{\prime}-2^{\prime}$ axes systems will be nearly co-incident. As the matrix looses its in-situ shear stiffness, local shear strain, $\gamma_{12}$, will start to rise rapidly. It can be shown that the angle between the 1 -axis and the $1^{\prime}$-axis, given by $\phi$ and $\gamma_{12}$, for small strains, are related by

$$
\gamma_{12}=\gamma_{12}^{\infty}+\phi-\beta
$$

Here, $\gamma_{12}^{\infty}$ is the contribution from the externally applied shear loading, if any. For a uniaxial compression loading and assuming $\beta=\beta_{0}=0$, we arrive at,

$$
\gamma_{12} \approx \phi
$$




\section{B. Numerical Implementation via the Finite Element (FE) Method}

The material behavior outlined in the previous subsection is modeled in the numerical domain using the commercially available FE package ABAQUS. ABAQUS has the capability of integrating user defined material behavior with its existing element library through user defined material subroutine, UMAT ${ }^{19}$. This subroutine is called at each material point for which the constitutive law is defined through the user defined option. A UMAT receives from the solver in ABAQUS, the stresses and strains from the previous loading step, the increment of strain in the current loading step and various other parameters. After calculations, the UMAT returns to the solver the updated stresses and internal state variables, if any, and the incremental tangent stiffness matrix, $\partial \sigma_{i j} / \partial \epsilon_{i j}$. Here it is pertinent to relate the three reference frames described in the previous subsection to the finite element solver reference systems. The $x-y$ reference frame is the 'global' or 'laminate' frame. The master geometry of the numerical domain is defined in this system. We will also use this frame to define external loading. The $1-2$ reference frame coincides with the 'local' lamina orientation, without any loss in its significance. The solver in ABAQUS passes variables to a UMAT in this coordinate frame. The $1^{\prime}-2^{\prime}$ reference frame is the 'instantaneous' frame, with the $1^{\prime}$ direction coincident with the current fiber direction, and is used for computations within the UMAT. A description of the computation steps performed within the UMAT (which is also presented in Figure 4) is now given. In the n-th loading increment, the solver sends in the stresses $\sigma_{i j}^{n-1}$ in the $1-2$ coordinate frame which are related to the stresses in the $x-y$ frame via the plane-stress transformation relation,

$$
\begin{aligned}
\sigma_{11}^{n-1} & =\cos ^{2} \theta \sigma_{x x}^{n-1}+\sin ^{2} \theta \sigma_{y y}^{n-1}+2 \cos \theta \sin \theta \tau_{x y}^{n-1} \\
\sigma_{22}^{n-1} & =\sin ^{2} \theta \sigma_{x x}^{n-1}+\cos ^{2} \theta \sigma_{y y}^{n-1}-2 \cos \theta \sin \theta \tau_{x y}^{n-1} \\
\tau_{12}^{n-1} & =\cos \theta \sin \theta\left(\sigma_{x x}^{n-1}-\sigma_{y y}^{n-1}\right)+\left(\cos ^{2} \theta-\sin ^{2} \theta\right) \tau_{x y}^{n-1}
\end{aligned}
$$

The strains $\epsilon_{i j}^{n-1}$ and strain increments $\mathrm{d} \epsilon_{i j}^{n}$ in the local $1-2$ coordinate system are also passed in from the solver. Within the UMAT, these local strain increments are added to the total strains to obtain the total strains $\epsilon_{i j}^{n}$. These strains, $\epsilon_{i j}^{n}$ are then transformed to the $1^{\prime}-2^{\prime}$ system using the angle between the local and the instantaneous frames, $\phi^{n-1}$, to obtain total strains in the instantaneous direction, $\epsilon_{i^{\prime} j^{\prime}}^{n}$. If the stored value of $S_{r}$ (solution from the previous load increment) is greater than $S_{r}^{*}$, all material parameters are degraded in a pre-determined fashion such that a zero secant stiffness state is reached asymptotically. If $S_{r}<S_{r}^{*}$, then these strains, $\epsilon_{i^{\prime} j^{\prime}}^{n}$ are used in Eq. (15) to solve for the thermodynamic damage variable $S_{r}$. If the $S_{r}$ value thus obtained satisfies Eq. (13), then the material point accumulates damage and the lamina in situ moduli $E_{22}$ and $G_{12}$ are degraded according to the input data provided. If $S_{r}$ does not satisfy Eq. (13), then the in situ moduli are not changed from their previous values. This ensures that the material point never 'heals' and the moduli always degrade monotonically. Subsequently, the material secant constitutive matrix, $Q_{i^{\prime} j^{\prime}}^{n}$ is computed using the in situ moduli, $E_{11}, \nu_{12}, E_{22}$ and $G_{12}$. According to the present modeling scheme, $E_{11}$ is not affected by $S_{r}$. Thus it remains constant at the undamaged state value for $S_{r}$ i $S_{r}^{*}$. Next, the stresses $\sigma_{i^{\prime} j^{\prime}}^{n}$ are updated and the material incremental constitutive matrix, $\partial \sigma_{i^{\prime} j^{\prime}} / \partial \epsilon_{i^{\prime} j^{\prime}}$ is computed.

When the increment of shear strain is small, then the instantaneous fiber rotation can be equated to the change in shear strain $\mathrm{d} \gamma_{1^{\prime} 2^{\prime}}^{n}{ }^{15}$. From the constitutive relation one can also write,

$$
\gamma_{1^{\prime} 2^{\prime}}^{n}=S_{66}^{n} \tau_{1^{\prime} 2^{\prime}}^{n}
$$

where, $S_{66}=1 / G_{12}$. Taking differentials on both sides of Eq. 19,

$$
d \gamma_{1^{\prime} 2^{\prime}}^{n}=S_{66}^{n} d \tau_{1^{\prime} 2^{\prime}}^{n}+d S_{66}^{n} \tau_{1^{\prime} 2^{\prime}}^{n}
$$

Equation (20) provides an expression for the change in angle $\mathrm{d} \phi^{n}$. This change is added to the fiber angle value of the previous step to obtain the current fiber angle $\phi^{n}$.

$$
\phi^{n}=\phi^{n-1}+d \phi^{n}
$$

This angle is used in the current increment, to transform the stresses and the material incremental constitutive matrix computed in the $1^{\prime}-2^{\prime}$ frame to the $1-2$ frame, to return to the solver in ABAQUS. In the absence of damage (or when the damage is small) the angle $\phi^{n}$ will be small. But with the accumulation of damage, $\phi^{n}$ starts to increase leading to local fiber direction instability. It should be noted that the definition of fiber rotation via Eq. (20) allows the possibility of elastic rotation recovery that is instrumental in deformation localization during kink banding. The steps outlined in this section are repeated at each loading increment until the analyses are completed. 


\section{Numerical Simulations}

The predictive capabilities of the present PFA methodology is assessed by simulating the experimental results of the panels described in McGowan et $\mathrm{al}^{9}$. Multiple test sections are modeled in the present work. Based on the orientation of the notch with respect to the loading direction ( $\alpha$ in Figure 1$)$ these panels are referred as P90 $\left(\alpha=90^{\circ}\right), \mathrm{P} 45\left(\alpha=45^{\circ}\right)$ and P60 $\left(\alpha=60^{\circ}\right)$. For each panel, complete geometries are modeled and discretized using the shear deformable four noded (S4/S4R) shell elements available in ABAQUS. Figure 6 and Figure 7 show the discretized FE mesh for P90 and P60. Finite element discretization for the P45 panel is similar to the P60 panel. A summary of the nodal and elemental data is provided in Table 1.

For each panel, static analyses are performed using displacement control loading. An arc length solution method $^{20}$ is used through the RIKS option available in ABAQUS. Geometric nonlinearity is included in the response analysis through the NLGEOM option available in ABAQUS. Only one stack of $\left[ \pm 45 / 0_{2} / 90 / 0_{2} / \mp\right.$ 45] (nine layers) was modeled. The thickness of each layer was chosen as the total thickness of all similar orientations such that the total model thickness equals the total panel thickness. The present approach does not consider any out of plane damage mode which allows lumping layers with similar orientations in this manner.

Elastic material properties for the $\mathrm{CNP}^{9}$ material systems are described in Table 2. Nonlinear stressstrain curves in shear ${ }^{21}$ and in transverse compression/tension for these material systems are shown in Figure 5. A material point is denoted as 'damaged' when it reaches the end of the input stress-strain curve. For the present analysis, this refers to a $55 \%$ degradation in the in situ shear modulus, $G_{12}$. Complete material constitutive behavior is modeled via the user material subroutine option of ABAQUS. Section lay-up of the laminates are defined using the *SHELL SECTION, COMPOSITE option available for shell elements. Thickness effects are incorporated by using multiple integration points through the thickness.

Boundary conditions for the panels are applied at nodal positions. A uniform displacement is applied at the top of the panel (side BC, Figure 1). Bottom of the panel is constrained from moving. Sides perpendicular to these two edges (perpendicular to the notch axis for P90 panel) are kept at a stress free configuration. A column of nodes near the left and right edges of the panel is subjected to a simple-support condition to mimic the knife edge supports used in the experiments.

Geometric and material perturbations are both used in the CNP analysis. Material axis system of the axial layers $\left(0^{0}\right.$ layers $)$ are offset from the 2-direction by a pre-specified amount, $\theta$. Multiple values of $\theta$ $\left(0^{0}-2^{0}\right)$ is used in the analysis. For other layers, perfectly aligned fibers are considered.

\section{Results for the Structural Panels}

Results from the FE predictions of CNP tests are presented in the current section. Load-vs.-load point deflection $(\mathrm{P}-\Delta)$ data and axial strain gage data from the experiments are compared with the $\mathrm{FE}$ analysis predictions. McGowan et $\mathrm{al}^{9}$ provide the strain gage locations as the locations of the mid-points of the physical strain gages. These gages are of finite size and being located in a sharp strain gradient zone, provide an averaged value of strain over the area they occupy. From the numerical analysis, an area is chosen for each strain gage and an averaged value of axial strain over that area has been compared against the test data of the corresponding strain gage. A similar approach is followed for the P60 and P45 test results. Contours of damage growth, expressed as contours of in-situ shear modulus $G_{12}$ are also presented to show damage evolution.

\section{A. P90 panel results}

\section{Load-vs.-Load point displacement}

Load-vs.-Load point displacement (or P- $\Delta$ ) data for the P90 panel is plotted in Figure 8. Responses corresponding to case 1 and case 2 are shown with the experimental data. The FE responses match the slope of the experimental data, corroborating the validity of the undamaged initial elastic moduli. The experimental peak load is observed at $635 \mathrm{KN}$. Peak load prediction from the present PFA is $650 \mathrm{KN}$ which is within $3 \%$ of the test data (Table 3). As mentioned earlier, the material degradation data (in-situ $E_{22}$, $G_{12}$-vs.- $\left.S_{r}\right)$ for this laminate material was not available. Hence the degradation model of a similar material system has been used. This introduces an uncertainty in the predictive model and possibly leads to the difference between the PFA and the experimental results. 
Cases 2 through 4, constitutes the material imperfection signature of the panel. It is not possible to accurately determine the material angle imperfection in a lamina. Thus it is prudent to study the behavior of the panel over a range of possible imperfection angles. The set of possible imperfection angles (or fiber misalignment angles) constitutes the 'material imperfection signature' of a panel. As can be observed from the results presented in Figure 9, the peak load is rather insensitive to the material and geometric imperfections. This is due to the fact the stress concentration of the notch is strong enough to overshadow other types of imperfections present in the system. As the notch radius becomes larger in proportion to the panel thickness, the fiber misalignment starts to influence the peak load as has been shown in earlier work ${ }^{22}$.

Damage contours

Damage contours for the P90 panel are plotted at various loading steps. These steps are tabulated in Table 4. Damage contours are plotted as contours of in-situ shear modulus $G_{12}$ for different layers at given external displacements (Figure 10-Figure 13). The damage accumulation state variable $S_{r}$ is driven by the local shear strain $\gamma_{12}$, thus this measure of the in-situ shear modulus is appropriate to depict damage progression. Areas which have lost more than $55 \%$ of their undamaged in-situ shear modulus are termed 'damaged' and are colored black. A color closer to red denotes higher percentage of remaining shear stiffness (or less damage) with red representing undamaged or minimally damaged values. Damage is seen to originate near the notch tips in the $45^{\circ}$ layer (Figure 10) at an external load level of $290 \mathrm{KN}$. The other layers also accumulate damage with the $0^{0}$ (or axial) layer showing the least accumulation up to this load level. Figure 14 shows the rate of damage evolution at a location near the notch tip captured through the thickness of the lamina. The off axis layers $\left( \pm 45^{0}, 90^{0}\right.$ layers) degrade at a faster rate compared to the axial layers $\left(0^{0}\right)$. The rate of damage accumulation increases in the axial layers when the off axis layers exceed $S_{r}^{*}$. Figure 11 shows the damage state in various layers when $S_{r}^{*}$ is reached for the very first time in the axial layers (at $380 \mathrm{KN}$ ). Figure 12 shows the contours of in-situ shear modulus distribution when the peak load is reached. It can be seen that the damage zone in the axial layers is yet to reach the edge of the panel. It can be also seen that the damage zone in the axial layers does not grow perpendicular to the loading direction, rather in an oblique fashion. Figure 15 shows the damage growth direction and the experimental observations from McGowan et al. ${ }^{9}$ The damage zone can be seen to reach the edge of the panel (in the axial layer) when the peak load is about $510 \mathrm{KN}$ Figure 13). When the damage zone reaches the edge of the panel, it essentially severs the load carrying path between the two ends of the panel, thus rendering it unable to carry any further load.

Stress evolution ahead of notch tip

Another marker which can be used to track damage growth, is the stress evolution ahead of the notch tip. Figure 16 shows the $\sigma_{22}$ stress evolution of the $90^{\circ}$ layer ahead of the left notch tip. It can be seen from the data that, the notch creates a stress gradient with a stress concentration factor slightly in excess of 3 . The peak stress in the distribution is reached around an external load level of $325 \mathrm{KN}$. At this external load, the local material point 'fails' as per the definition given earlier. Subsequently, the stress drops at this location and the peak stress location starts to move away from the notch tip towards the edge of the panel. It can be observed that as the 'failed' locations shed stress, the overall stress ahead of the 'peak' increases with increasing external load. The 'peak' of this stress distribution crosses $36 \%$ of the distance between the notch tip and the edge of the panel, before the overall panel 'peak load' is obtained. Peak of the local stress distribution eventually reaches the edge of the panel signaling complete exhaustion of load carrying capability of the panel (not shown in the figure).

Strain gage data

Strain gage readings from four strain gages used in the test are compared with the PFA predictions. These are plotted in against the applied end shortening in Figure 17. Gage 25 and gage 28 are placed along the notch axis. Gage 12 and gage 13 are away from the notch axis with gage 13 being in the load path of gage 28. From the results, it is seen that gage 13 and gage 12 results are in very good agreement with the test data. Gage 13 test data becomes non-linear near an end shortening of $1.2 \mathrm{~mm}$ which is captured by the PFA prediction for gage 13. Similarly, gage 12 test reading becomes non-linear and shows a strain reversal near $\Delta=0.8 \mathrm{~mm}$. This event is also captured by the PFA prediction. Location of gage 12 is near the notch tip but a little away from the notch axis. Thus the presence of strain reversal suggests load redistribution while damage progresses away from the notch tip. Gage 28 and gage 25 are both situated in regions having very sharp strain gradients. Thus the test data is prone to scatter. The PFA prediction for gage 28 shows a higher rate of strain increase compared to the test data. This can be attributed to the absence of any local imperfection modeling in the PFA. The PFA data show onset of nonlinear behavior near $\Delta=0.9 \mathrm{~mm}$ which 
is similar to the trends shown in test data. Gage 25 is situated ahead of the notch which has the steepest strain gradient. In the numerical prediction, such locations are prone to the widest variation in predictions. Keeping this in mind, the slope of the PFA prediction is slightly higher than the test data but the trends show similar features.

\section{B. P60 panel results}

\section{Load-vs.-Load point displacement}

Load-vs.-Load point displacement (or P- $\Delta$ ) data for the $\mathrm{P} 60$ panel is plotted in Figure 18. The test data shows a region of settling which is absent in numerical modeling. Taking this into account, the initial slopes of the PFA prediction and the test data matches well. The experimental peak is reported at a load level of $690 \mathrm{KN}$ at an end shortening of $1.2 \mathrm{~mm}$. The present PFA predicts a peak load of $720 \mathrm{KN}$ which is within $4 \%$ of the test data. Beyond the peak, the response shows a near vertical drop in load. At this stage the damage zone in the axial layers progress rapidly towards the edges of the panel. When the zones reach the panel edges, the P- $\Delta$ response shows slight unloading. The unloading is arrested and the response ultimately reaches a load plateau near $20 \mathrm{KN}$ when the panel looses all its load carrying capacity.

Strain gage data

Strain gage locations for which the test data are compared against the PFA predictions, are shown in Figure 19. Gage 14 is located near the notch tip which has a steep strain gradient. This is a possible source of variation when the test data is compared with numerical predictions. Gage 13 and 14 are also located along the same line joining gage 14 with the notch. These three gages are situated on the possible path of damage progression. Two other gages are located a little away from the damage path but along the load paths of gage 11 (gage 26) and gage 13 (gage 27).

Figure 20 shows the strain gage data plotted against the end shortening. Test data and PFA predictions for gage 26 show good agreement. Similar agreement is also observed for gage 27 . Near $\Delta=1.1 \mathrm{~mm}$, readings from these two gages become nonlinear indicating a failure event. The PFA predictions show a strain reversal indicating load redistribution which stems from a global failure event. Gage 11 reading from the test data deviates away from the PFA prediction, indicating the presence of a strong local imperfection which is not modeled in the present work. However, both sets of data become nonlinear near the same $\Delta$ which indicates that the underlying phenomenon has been captured properly. Gage 14 data from the test compares well with the PFA prediction. The PFA prediction show a large strain increase near $\Delta=0.75 \mathrm{~mm}$ indicating a failure zone passing through the gage location. The test data shows such sign of failure near 0.8 $\mathrm{mm}$.

\section{P45 panel results}

\section{Load-vs.-Load point displacement}

For the P45 panel, overall P- $\Delta$ data is not available. Hence the FE response can not be directly compared to the test data. However, McGowan et al. ${ }^{9}$ reports that this panel supports a maximum load of $720 \mathrm{KN}$ at an end shortening displacement of $1.33 \mathrm{~mm}$. From the present work, a peak load of $780 \mathrm{KN}$ is predicted at an end shortening of $1.49 \mathrm{~mm}$. This prediction is within $10 \%$ of the peak load. This panel is modeled without any local imperfection or out-of-plane motion. This is a possible source of disagreement between the PFA prediction and the test data.

Strain gage data

Readings from five strain gages used in the test of the P45 panel are compared against the numerical predictions. Three of these gages (gage 11, gage 13 and gage 14) are situated along the damage path. Two other gages are away from the damage path but are along the load paths of gage 11 (gage 26) and gage 13 (gage 27). Axial strain date from the PFA prediction are plotted against the applied end shortening in Figure 21. Predictions of strain gages 13 and 14 show excellent agreement with the test data. Prediction for gage 11, shows a steeper rate of strain accumulation compared to the test data. This is possibly due to the absence of any out-of-plane effect (presence of which could add a local bending component to the strain gage data). Predictions from all three strain gage readings show an increase in strain indicating catastrophic failure. The test data showed large strain reversal which also indicates catastrophic failure and presence of local out-of-plane imperfections. Predictions for strain gages 26 and 27 also show good agreement. Readings

from these two gages show a strain reversal near the same end shortening when readings from gage 11, 13 and 14 become nonlinear. This indicates load redistribution during the global failure event. 


\section{Concluding Remarks}

In this paper, a failure mechanism based progressive failure analysis methodology is validated against experimental data for a set of structural panels. The methodology uses the complete non-linear stress-strain relations for the lamina in shear and in transverse tension/compression as input, along with readily available lamina level elastic properties. Using only these (a minimum number) as inputs, progressive failure and damage growth in a set of structural panels, loaded under a compression loading have been simulated. In particular by modeling the physics of the kink banding process responsible for limiting the lamina axial compression strength, the maximum load sustained by the panels and the subsequent damage evolution is captured. The present analysis approach is seen to capture the peak load predictions within $10 \%$ of the experimental predictions for three different notch orientations. The present approach has also captured the damage progression during the loading history. The strain gage readings from various locations on the test panel are compared against the PFA predictions. The good agreement between test and prediction for global structural level quantities and local quantities (strain readings) of interest lends confidence to the proposed PFA strategy.

\section{References}

${ }^{1}$ Schapery, R. A., "A Theory of Mechanical Behavior of Elastic Media with Growing Damage and other Changes in Structure," Journal of the Mechanics and Physics of Solids, Vol. 38, No. 2, June 1990, pp. 215-253.

${ }^{2}$ Hashin, Z., "Failure Criteria for Unidirectional Fiber Composites," Journal of Applied Mechanics, Vol. 47, June 1980, pp. 329-334.

${ }^{3}$ Chang, F.-K. and Lessard, L. B., "Damage Tolerance of Laminated Composites Containing an Open Hole and Subjected to Compressive Loadings: Part I-Analysis," Journal of Composite Materials, Vol. 25, January 1991, pp. 2-43.

${ }^{4}$ Pinho, S. T., Dávila, C. G., Camanho, P. P., Iannucci, L., and Robinson, P., "Failure Models and Criteria for FRP Under In-Plane or Three-Dimensional Stress States Including Shear Non-Linearity," NASA/TM-2005-213530, February 2005.

${ }^{5}$ Dávila, C. G., Jaunky, N., and Goswami, S., "Failure Criteria for FRP Laminates in Plane Stress," $44^{\text {th }}$ SDM Conference, AIAA, Norfolk, April 2003.

${ }^{6}$ Schapery, R. A. and Sicking, D. L., "On Nonlinear Constitutive Equations for Elastic and Viscoelastic Composites with Growing Damage," Mechanical Behavior of Materials, Vol. 47, June 1995, pp. 45-76.

${ }^{7}$ Oguni, K., Tan, C. Y., and Ravichandran, G., "Failure Mode Transition in Unidirectional E-Glass/Vinylester Composites under Multiaxial Compression," Journal of Composite Materials, Vol. 34, No. 24, 2000, pp. 2081-2097.

${ }^{8}$ Basu, S., Waas, A. M., and Ambur, D. R., "Compressive Failure of Fiber Composites under Multiaxial Loading," Journal of the Mechanics and Physics of Solids, Vol. 54, No. 3, March 2006, pp. 611-634.

${ }^{9}$ McGowan, D. M., Dávila, C. G., and Ambur, D. R., "Damage Progression in Buckle-Resistant Notched Composite Plates Loaded in Uniaxial Compression," 42 ${ }^{\text {nd }}$ SDM Conference, AIAA, Seattle, April 2001.

${ }^{10}$ Basu, S., Waas, A. M., and Ambur, D. R., "Simulation of Progressive Failure in Multidirectional Composite Laminated Panels," Collected Papers in Structural Mechanics Honoring Dr. James H. Starnes, NASA/TM-2006-214276, February 2006.

${ }^{11}$ Basu, S., Waas, A. M., and Ambur, D. R., "Prediction of Progressive Failure in Multidirectional Composite Laminated Panels," in review, International Journal of Solids and Structures, 2006.

${ }^{12}$ Schapery, R. A., "Mechanical Characterization and Analysis of Inelastic Composite Laminates with Growing Damage," Mechanics of Composite Materials and Structures, Vol. AMD-100, June 1989, pp. 1-9.

${ }^{13}$ Sun, C. T. and Chen, J. L., "A Simple Flow Rule for Characterizing Nonlinear Behavior of Fiber Composites," Journal of Composite Materials, Vol. 23, October 1989, pp. 1009-1020.

${ }^{14}$ Dávila, C. G., Ambur, D. R., and McGowan, D. M., "Analytical Prediction of Damage Growth in Notched Composite Panels Loaded in Compression," Journal of Aircraft, Vol. 37, No. 5, September-October 2000, pp. 898-905.

${ }^{15}$ Schapery, R. A., "Prediction of Compressive Strength and Kink Bands in Composites using a Work Potential," International Journal of Solids and Structures, Vol. 32, No. 6/7, 1995, pp. 739-765.

${ }^{16}$ Lee, S. H. and Waas, A. M., "Compressive Response and Failure of Fiber Reinforced Unidirectional Composites," International Journal of Fracture, Vol. 100, No. 3, December 1999, pp. 275-306.

${ }^{17}$ Goyal, V. K., Jaunky, N., Johnson, E. R., and Ambur, D., "Intralaminar and Interlaminar Progressive Failure Analysis of Composite Panels with Circular Cutouts," $43^{\text {rd }}$ SDM Conference, AIAA, Denver, , No. AIAA 2002-1745, 2002 , pp. 1-12.

${ }^{18}$ Schapery, R. A., "Private communication," 2002.

${ }^{19}$ ABAQUS, v., ABAQUS User's Manual, Ver. 6.3-1, Hibbit, Karlson and Sorenson, Pawtucket, RI, 2003.

${ }^{20}$ Riks, E., "The Application of Newton's Method to the Problem of Elastic Stability," Journal of Applied MechanicsTransactions of the ASME, Vol. 39, No. 4, December 1972, pp. 1060-1065.

${ }^{21}$ Soden, P., Hinton, M. J., and Kaddour, A. S., "Lamina Properties, Lay-up Configurations and Loading Conditions for a Range of Fiber-Reinforced Composite Laminates," Composite Science and Technology, Vol. 58, 1998, pp. $1011-1022$.

${ }^{22} \mathrm{Ahn}$, J. H. and Waas, A. M., "Prediction of Compressive Failure in Laminated Composites at Room and Elevated Temperature," AIAA Journal, Vol. 40, No. 2, February 2002, pp. 346-358.

${ }^{23}$ Yerramalli, C. S. and Waas, A. M., "A Failure Criterion for Fiber Reinforced Polymer Composites under Combined Compression-Torsion Loading," International Journal of Solids and Structures, Vol. 40, No. 5, March 2003, pp. 1139-1164. 
Table 1. Summary of the finite element data.

\begin{tabular}{|c|c|c|c|}
\hline Panels & Nodes & Elements & Total d.o.f. \\
\hline P90 & 6324 & 6162 & 37944 \\
\hline P45 & 6266 & 6133 & 37596 \\
\hline P60 & 7004 & 6866 & 42024 \\
\hline
\end{tabular}

Table 2. Properties of the different prefabricated ply orientations CNPs ${ }^{9}$.

\begin{tabular}{|c|c|c|c|}
\hline \multirow{2}{*}{ Properties } & \multicolumn{3}{|c|}{ CNP } \\
\cline { 2 - 4 } & $\pm 45^{0}$ & $0^{0}$ & $90^{0}$ \\
\hline thickness $(\mathrm{mm})$ & 0.14986 & 0.15697 & 0.16967 \\
\hline$E_{11}(\mathrm{GPa})$ & 111.0 & 113.0 & 110.0 \\
\hline$E_{22}(\mathrm{GPa})$ & 11.0 & 11.0 & 11.0 \\
\hline$G_{12}(\mathrm{GPa})$ & 5.5 & 5.5 & 5.5 \\
\hline$G_{13}(\mathrm{GPa})$ & 5.5 & 5.5 & 5.5 \\
\hline$G_{23}(\mathrm{GPa})$ & 2.8 & 2.8 & 2.8 \\
\hline$\nu_{12}$ & 0.34 & 0.34 & 0.34 \\
\hline
\end{tabular}

Table 3. Comparison of test data and PFA predictions for peak load.

\begin{tabular}{|c|c|c|c|}
\hline Panel Type & $\begin{array}{c}\text { Test data } \\
\text { KN }\end{array}$ & $\begin{array}{c}\text { PFA prediction } \\
\text { KN }\end{array}$ & $\begin{array}{c}\text { Difference } \\
\%\end{array}$ \\
\hline P90 & 635 & 650 & 2 \\
\hline P60 & 690 & 720 & 4 \\
\hline P45 & 720 & 780 & 8 \\
\hline
\end{tabular}

Table 4. Load levels at which the damage contours are presented.

\begin{tabular}{|c|c|}
\hline Event & $\begin{array}{c}\text { Load level } \\
(\mathrm{KN})\end{array}$ \\
\hline Damage initiation in the top layer & 290 \\
\hline Damage initiation in the axial layers & 380 \\
\hline Peak load & 650 \\
\hline $\begin{array}{c}\text { Damage zone reaches edge of } \\
\text { panel (axial layers) }\end{array}$ & 510 \\
\hline
\end{tabular}




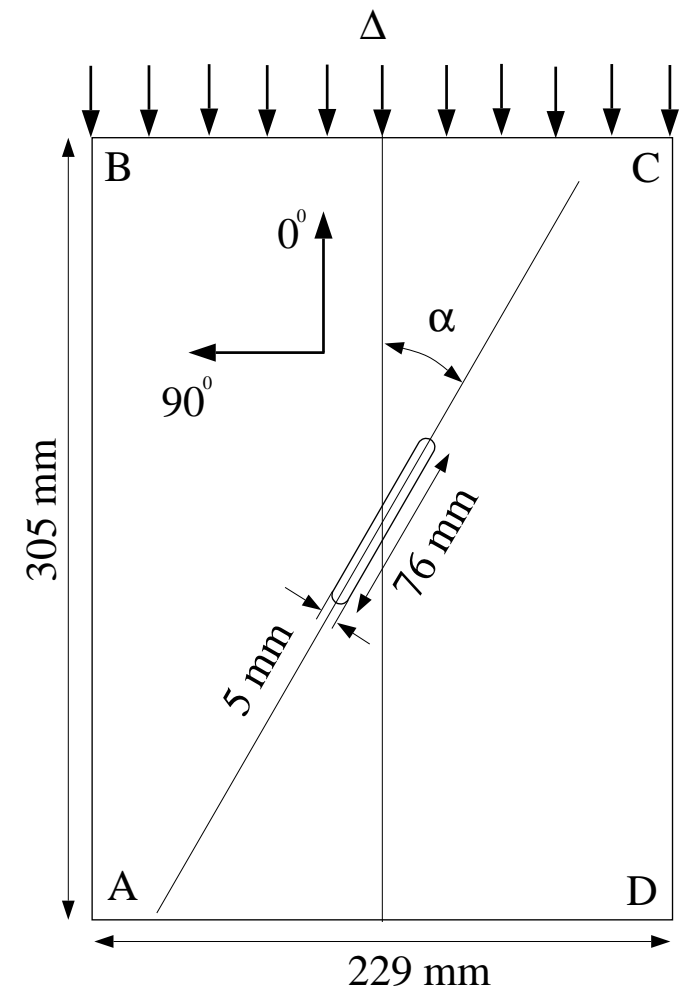

Figure 1. Schematic representation of a CNP specimen.

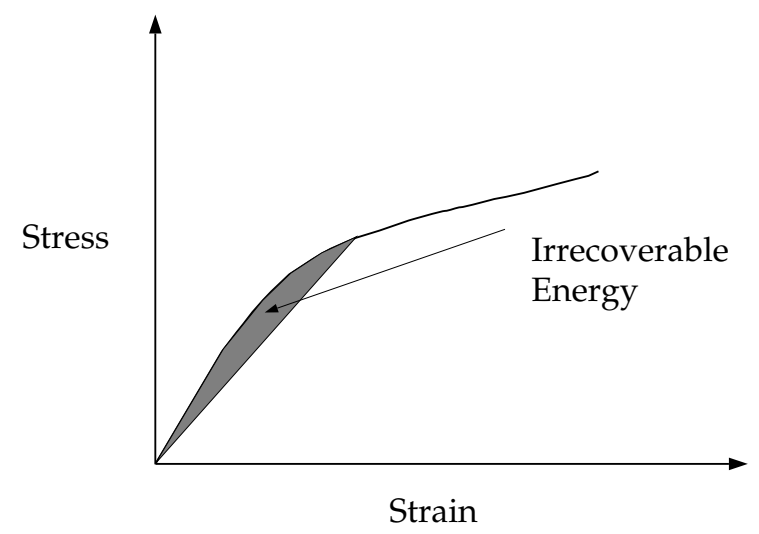

Figure 2. Definition of irrecoverable energy using a generic stress-strain curve. 


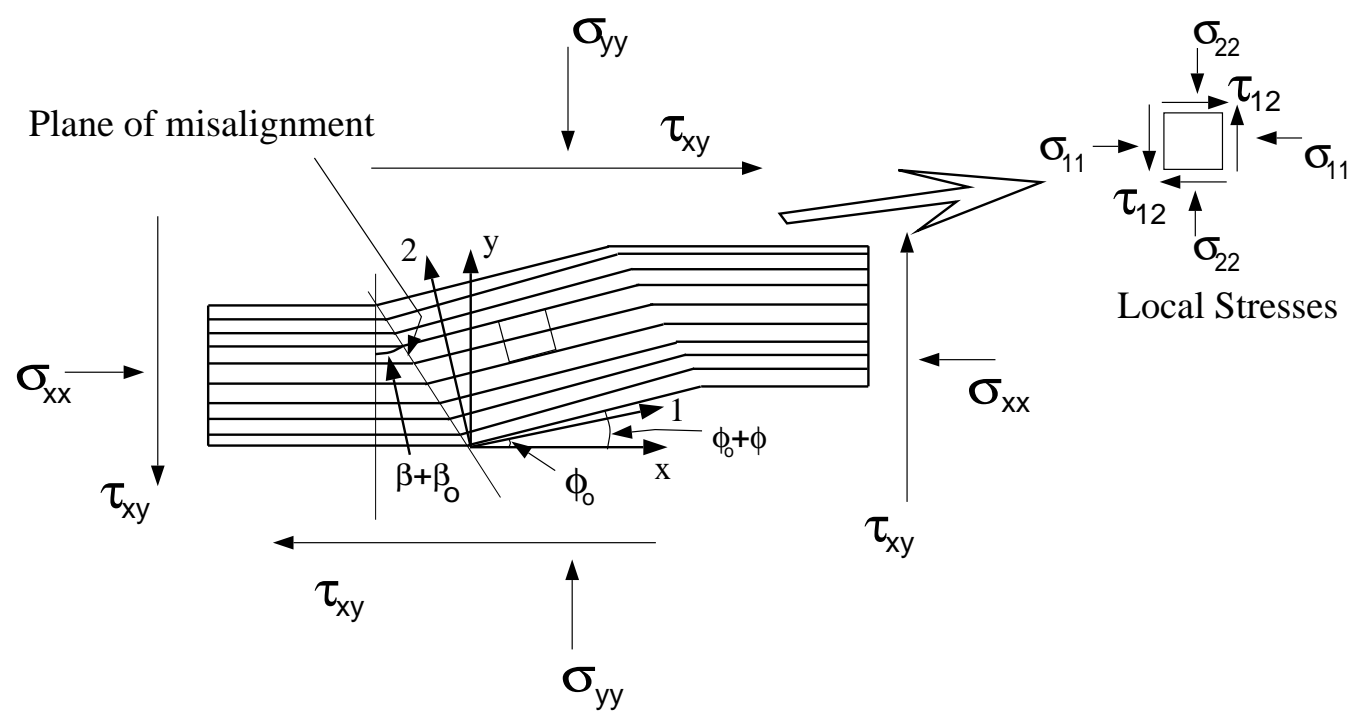

Figure 3. (a) A unidirectional lamina with a band of misaligned fibers in equilibrium under a multiaxial stress state. Inset shows the stress state inside the misaligned band.

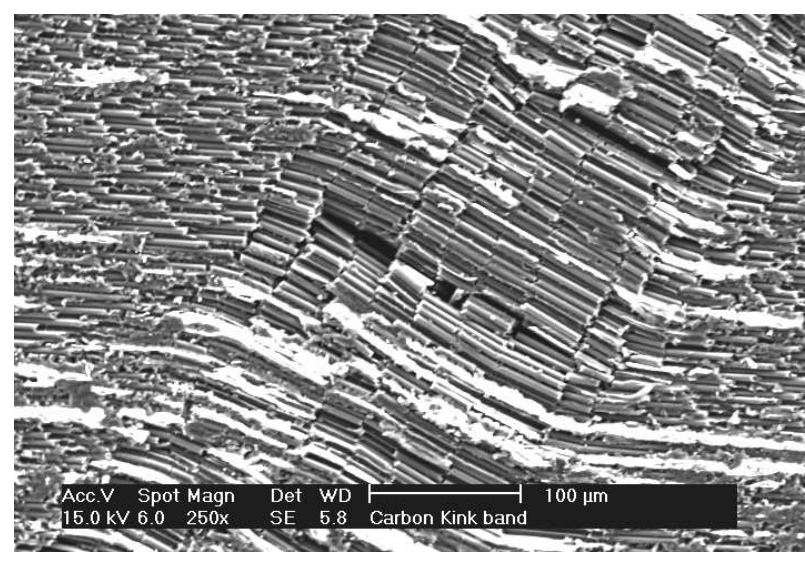

(a) Developing kink band

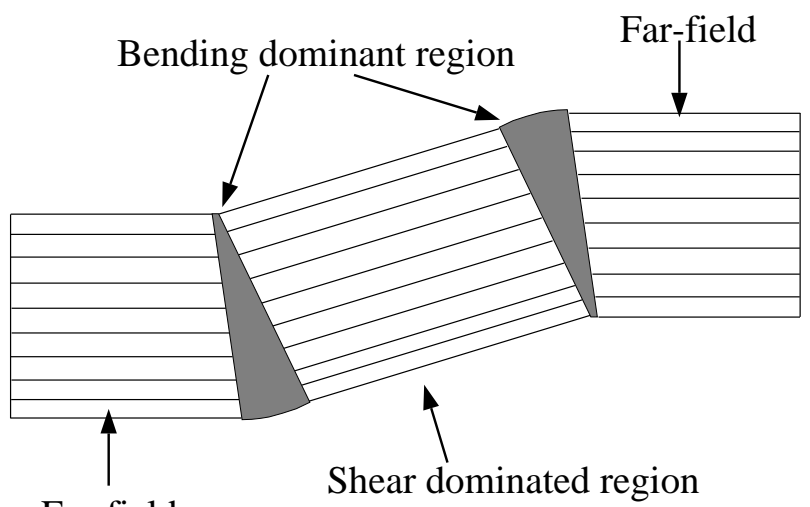

Far-field

Shear dominated region

(b) Schematic of a lamina

Figure 3(b, c) The developing kink band in Carbon composites ${ }^{23}$ and the schematic representation of such within a lamina ${ }^{8}$. 


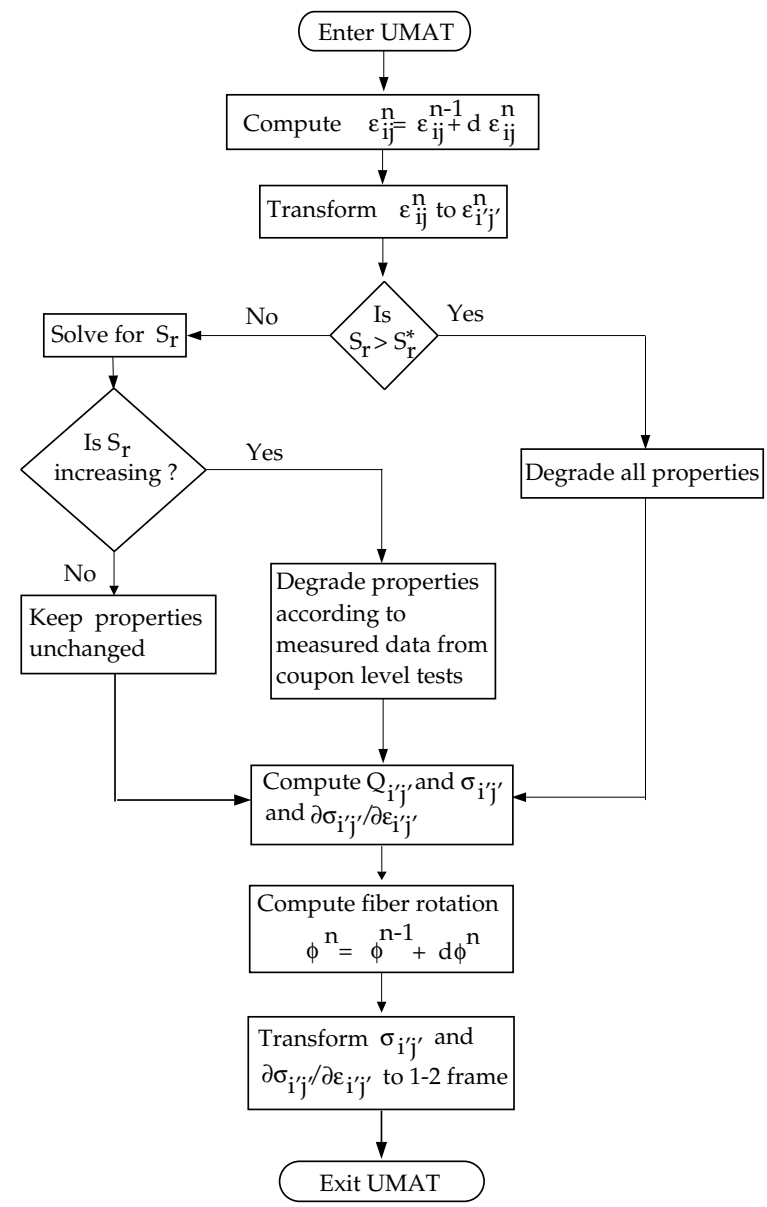

Figure 4. Flow chart of the operations performed inside a UMAT for implementing the fiber rotation and Schapery Theory ideas.

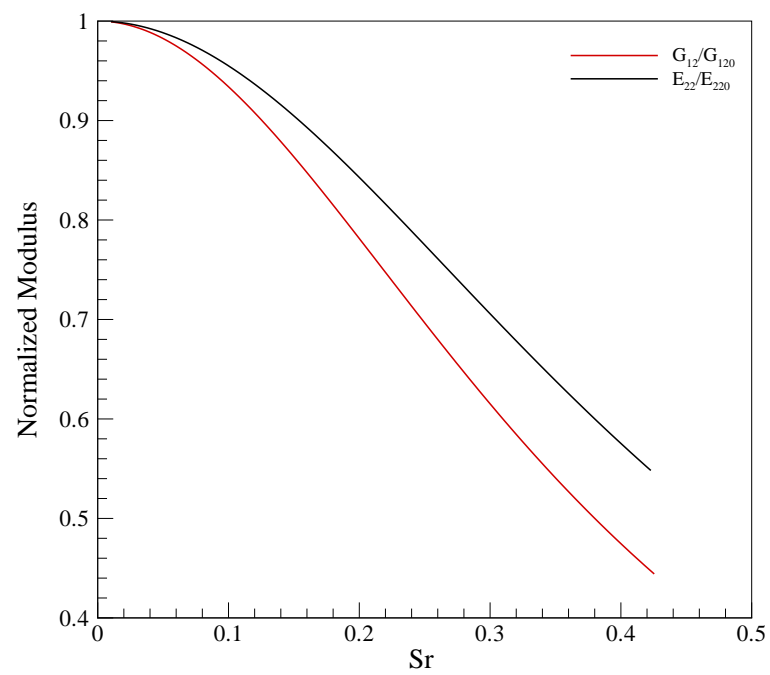

Figure 5. Normalized moduli plotted against the damage parameter $S_{r}$ 


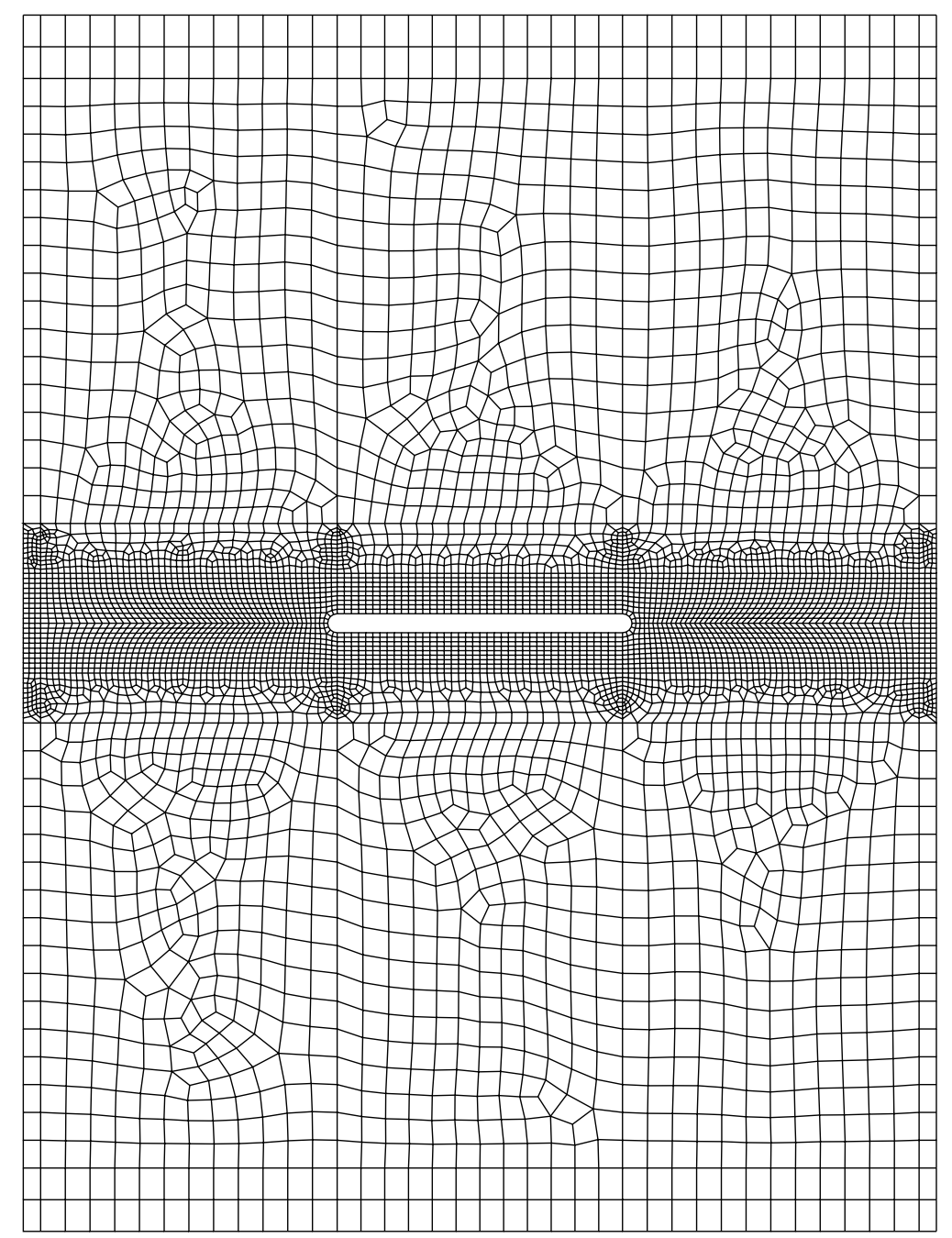

(a) Mesh used for P90 panel

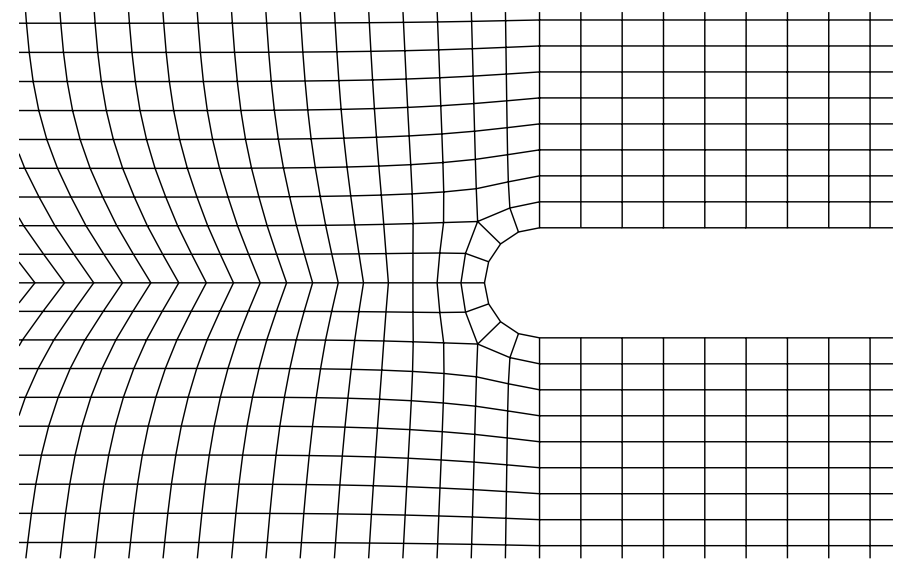

(b) Close up near notch tip

Figure 6. Complete FE mesh and close up near the notch tip for P90 panel. 


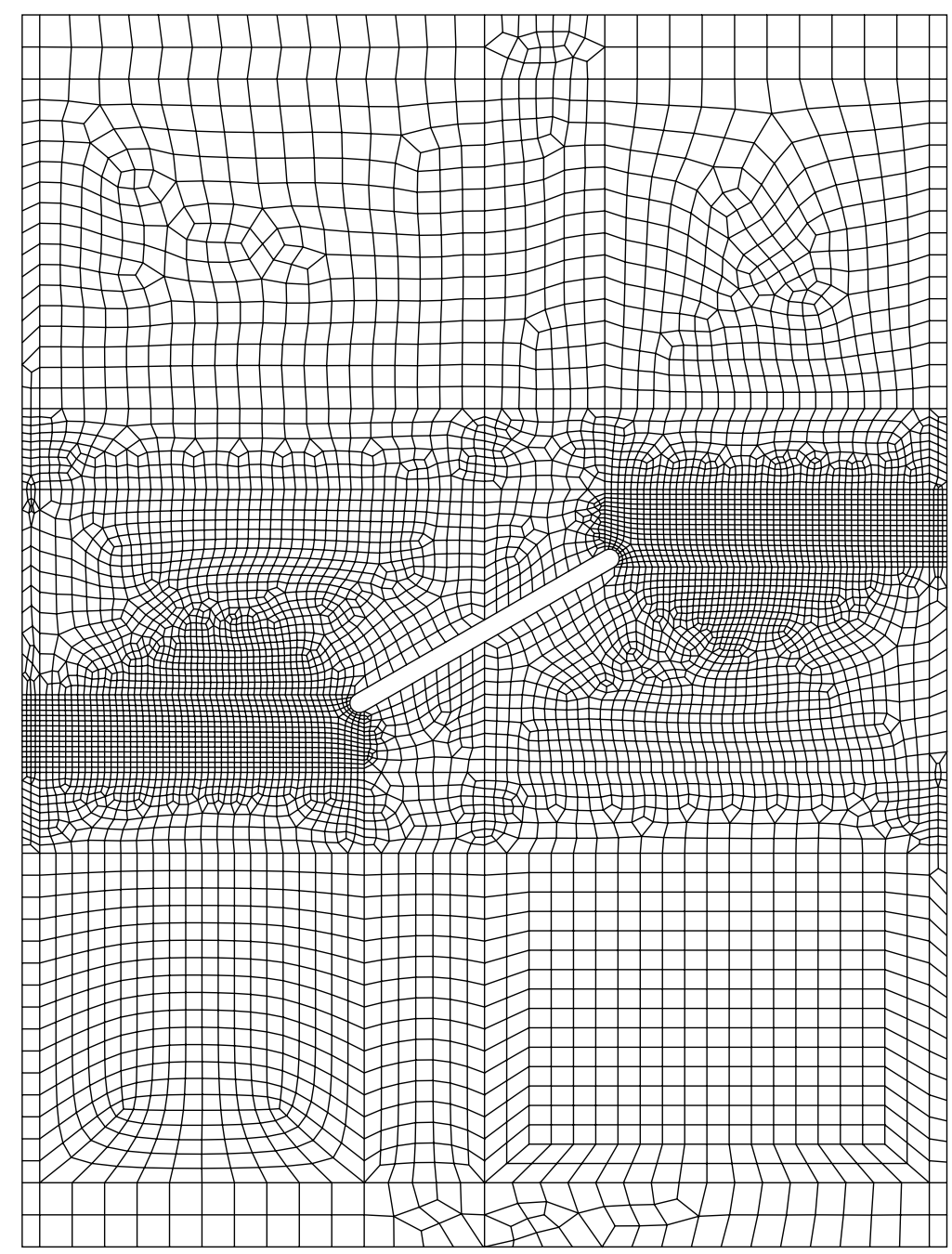

(a) Mesh used for P60 panel

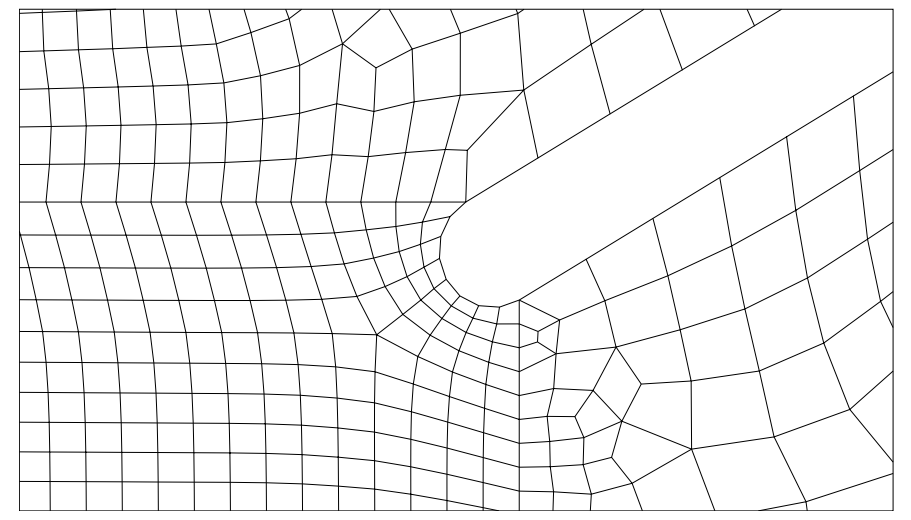

(b) Close up near notch tip

Figure 7. Complete FE mesh and close up near the notch tip for P60 panel. 


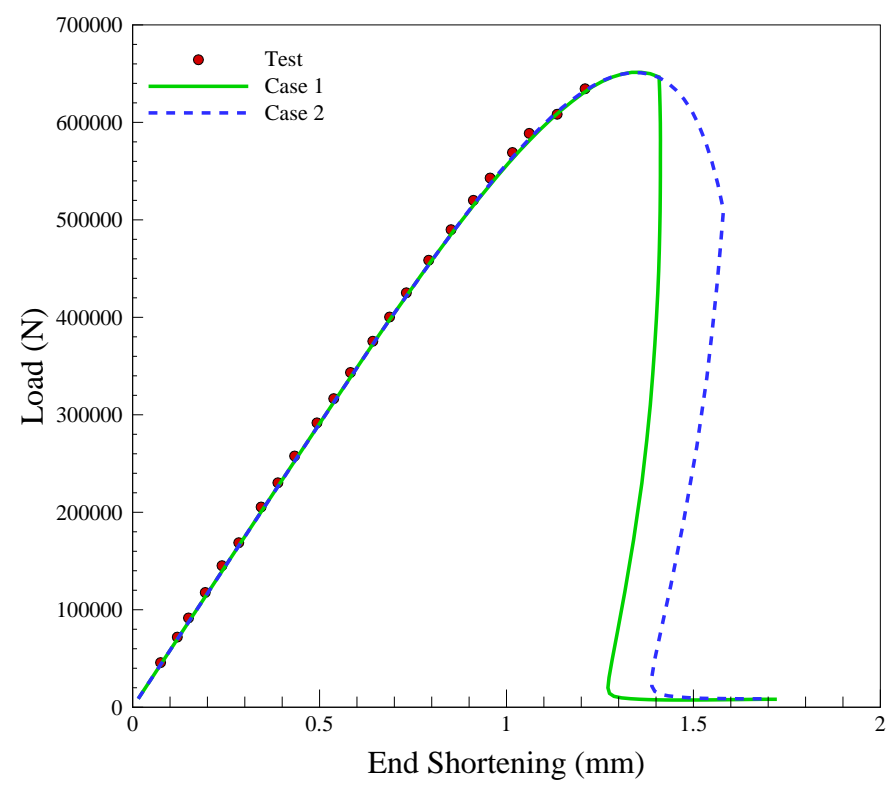

Figure 8. P- $\Delta$ response for case 1 and case 2 of the P90 panel.

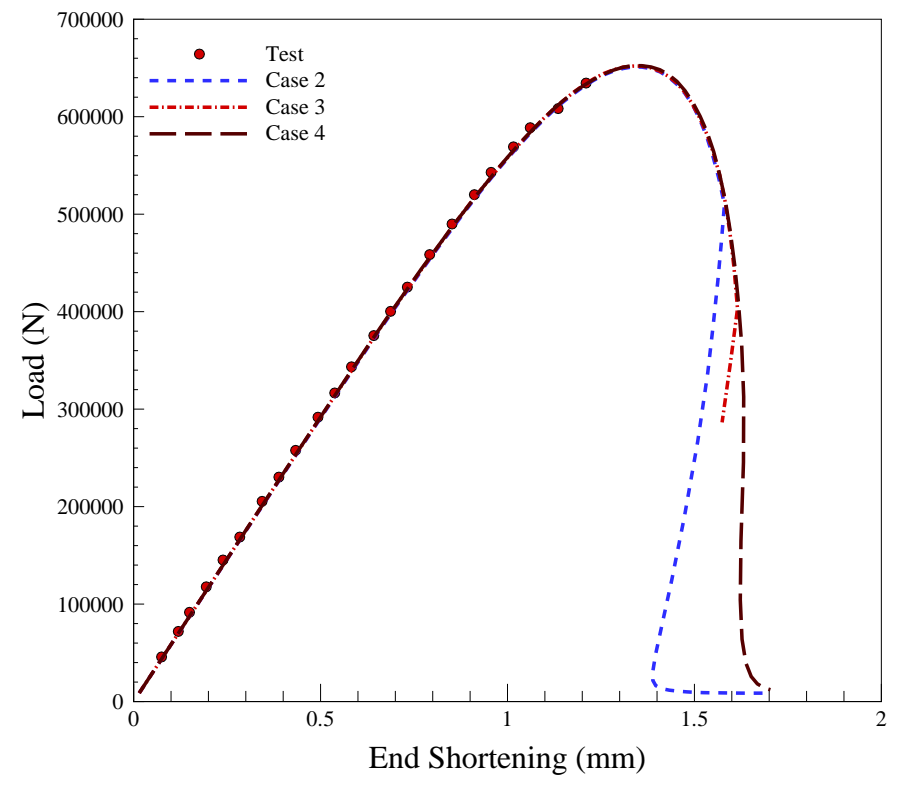

Figure 9. Material imperfection signature of the P90 panel. 


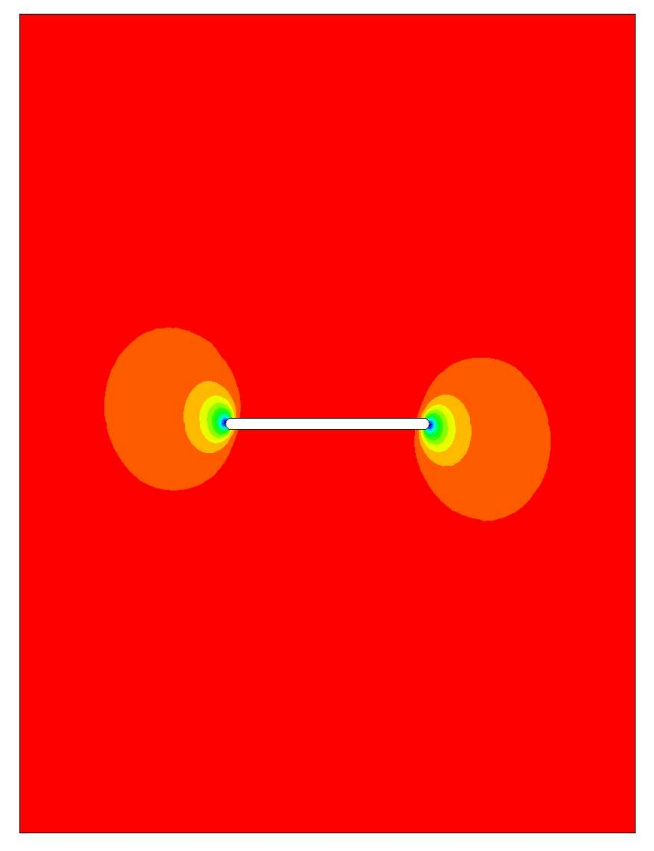

(a) $45^{0}$ Layer

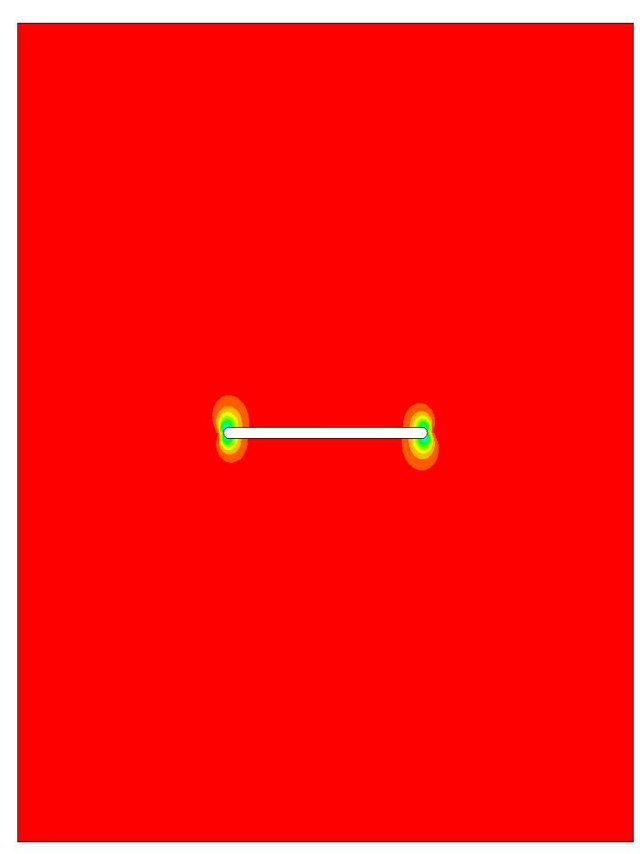

(c) $0^{0}$ Layer

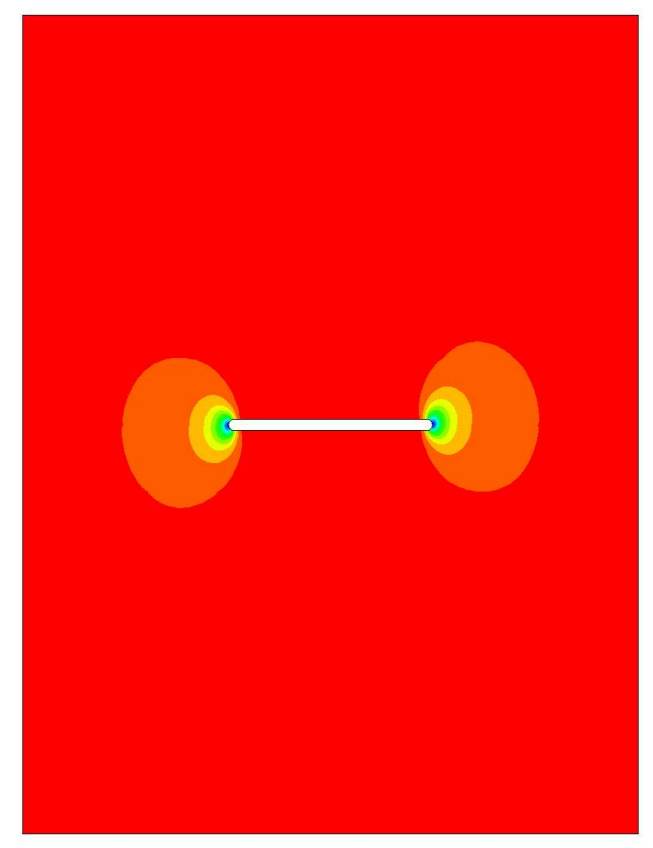

(b) $-45^{0}$ Layer

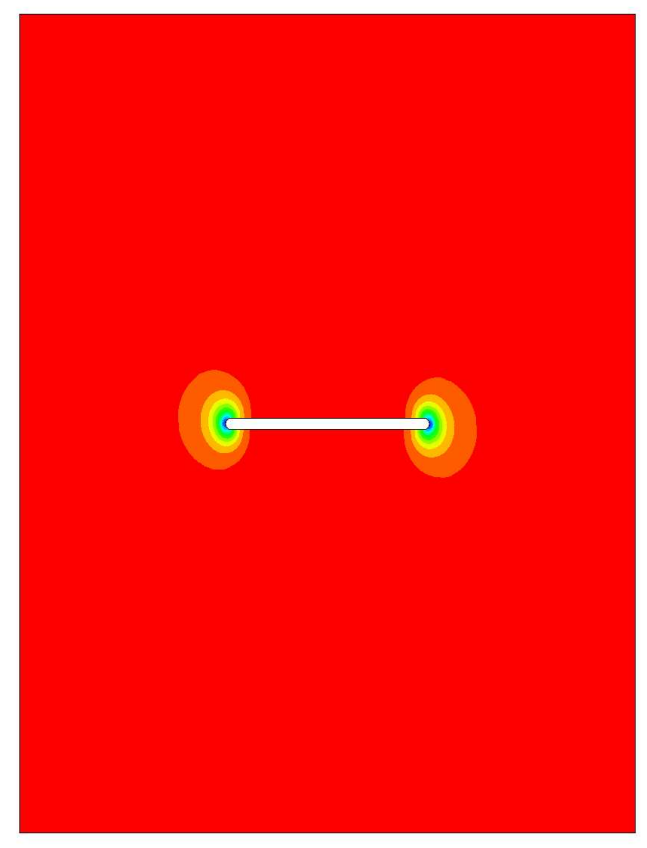

(d) $90^{0}$ Layer

Figure 10. Damage initiates in the outer layers, $P=290 \mathrm{KN}$. 


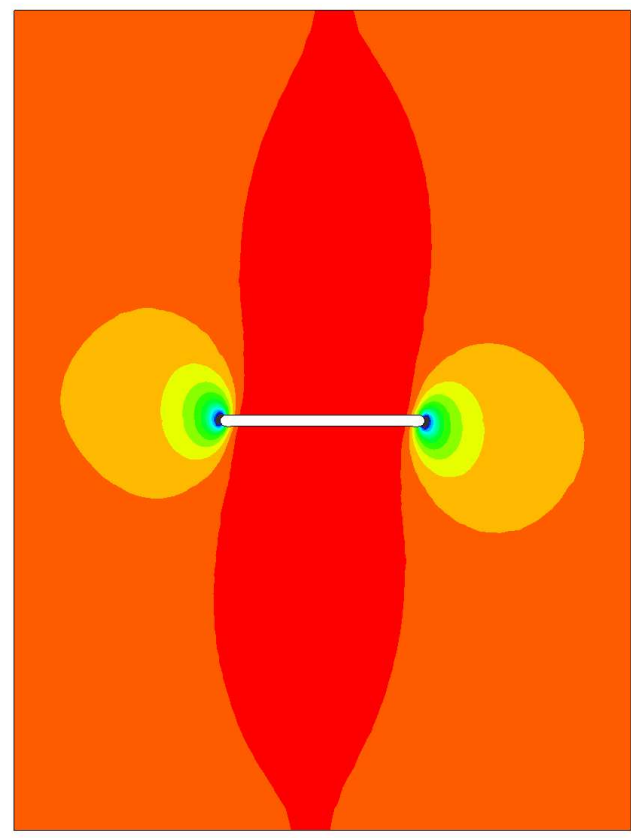

(a) $45^{0}$ Layer

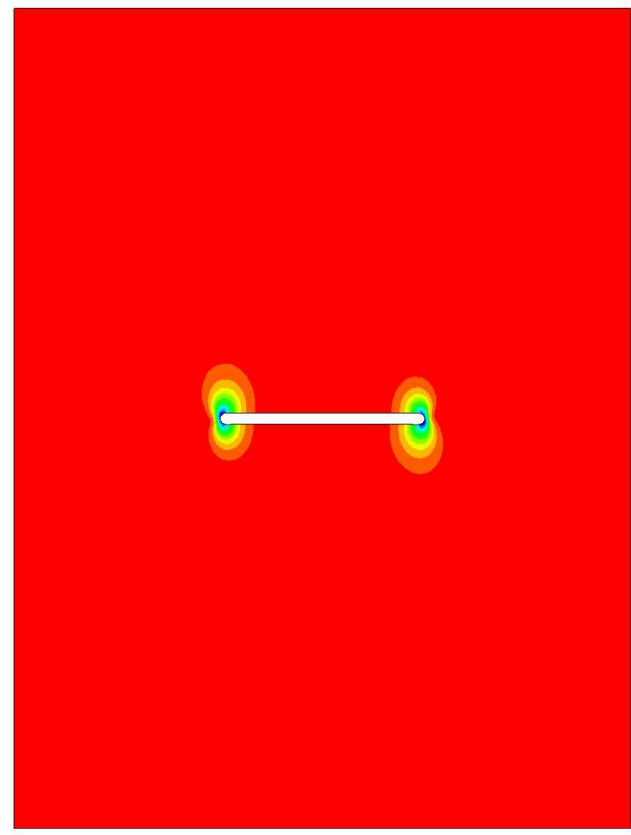

(c) $0^{0}$ Layer

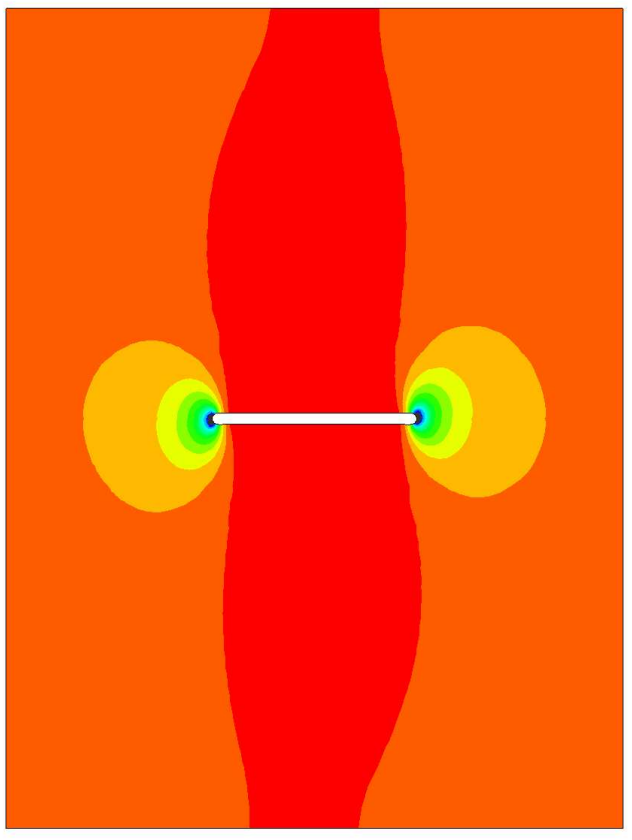

(b) $-45^{0}$ Layer

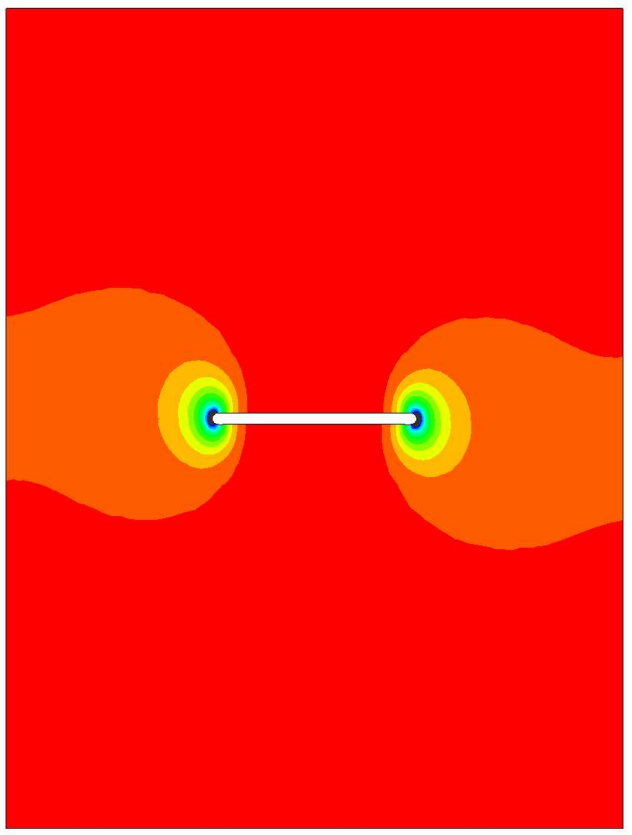

(d) $90^{\circ}$ Layer

Figure 11. Damage initiates in the axial layers, $P=380 \mathrm{KN}$. 


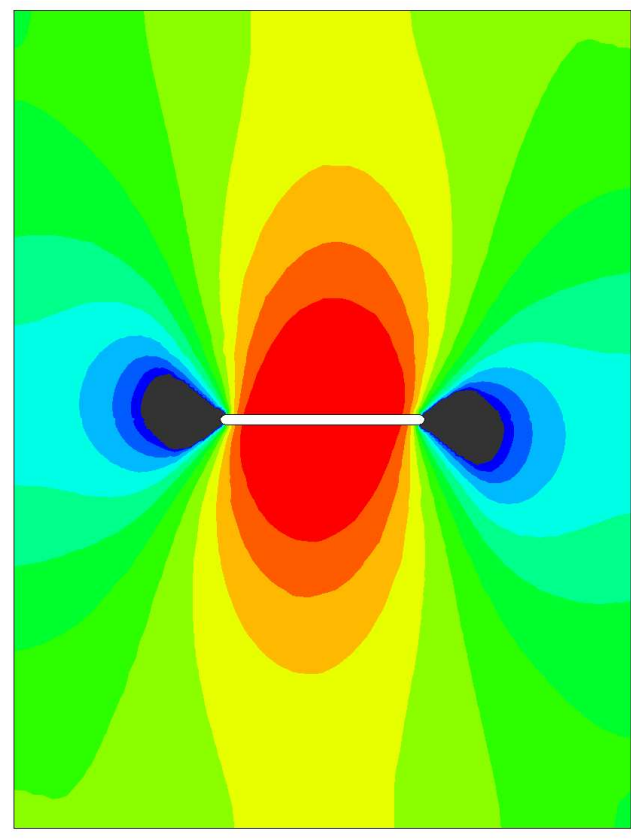

(a) $45^{0}$ Layer

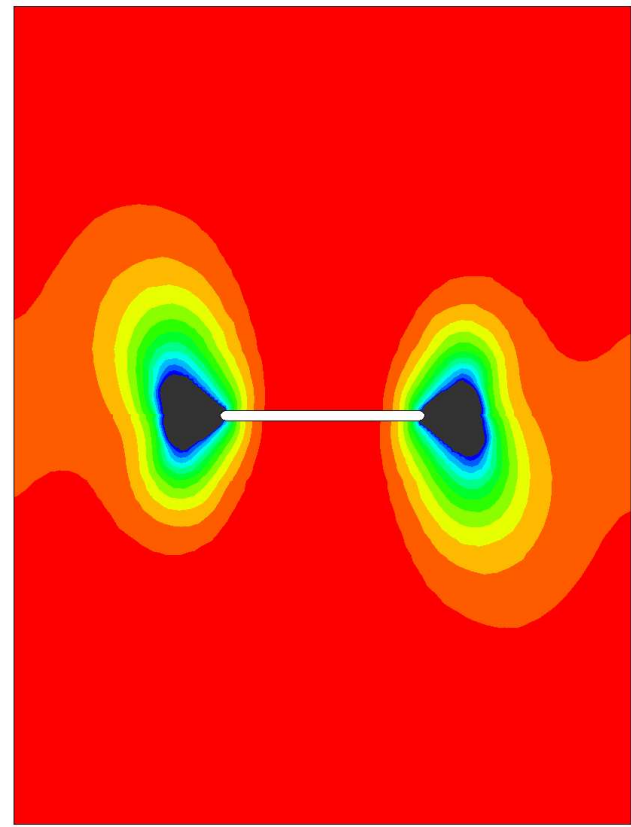

(c) $0^{0}$ Layer

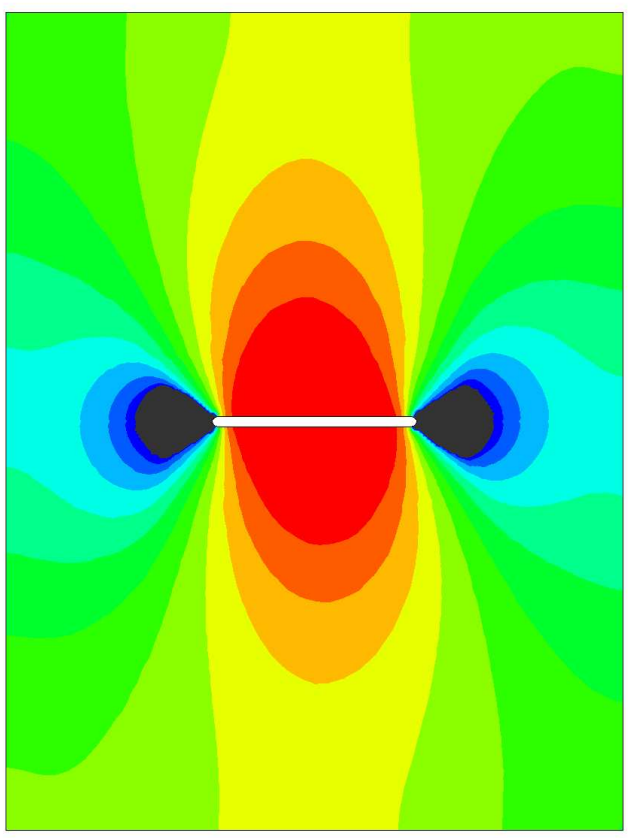

(b) $-45^{0}$ Layer

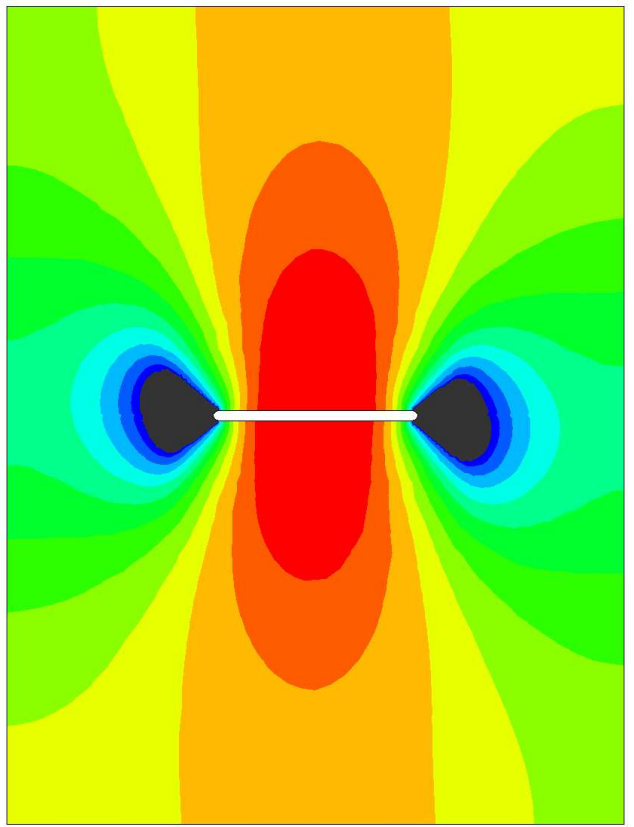

(d) $90^{0}$ Layer

Figure 12. Damage state at the peak load, $P=650 \mathrm{KN}$. 


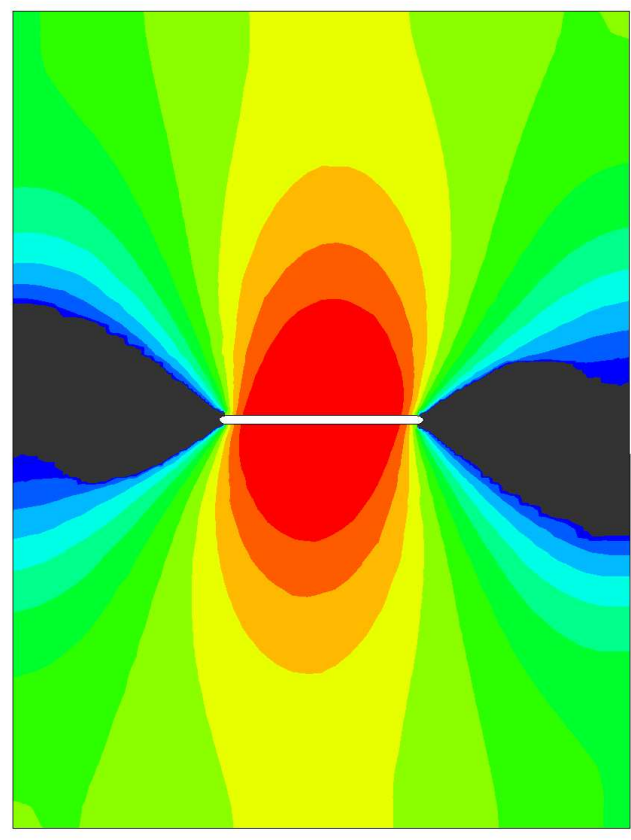

(a) $45^{0}$ Layer

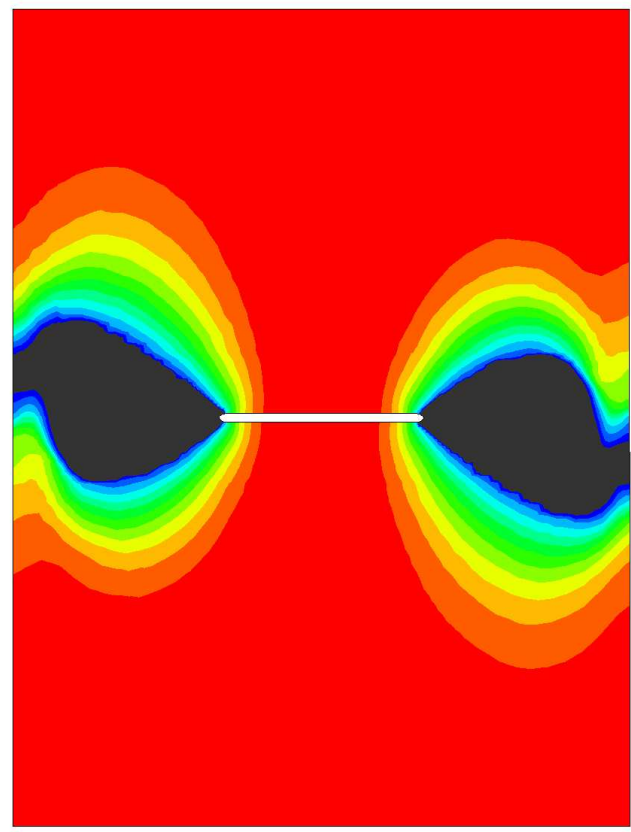

(c) $0^{0}$ Layer

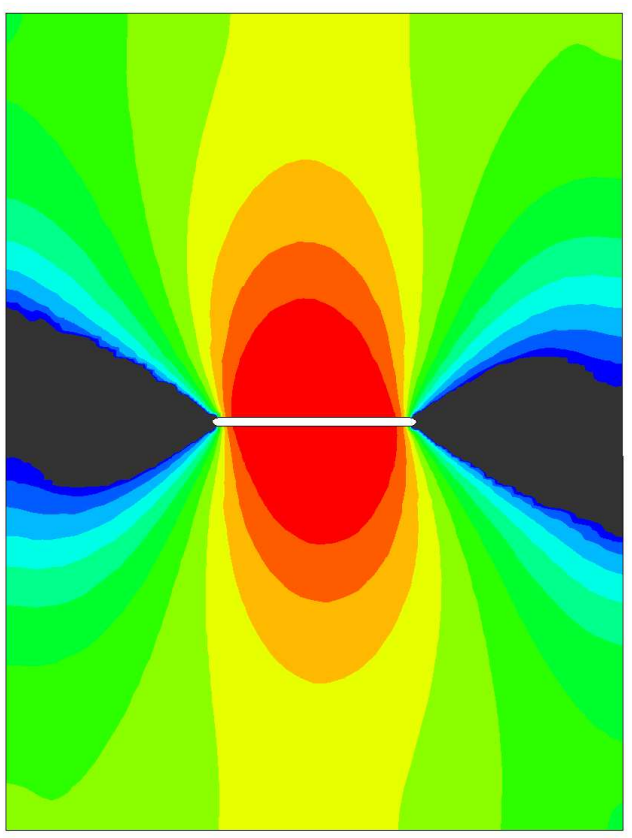

(b) $-45^{0}$ Layer

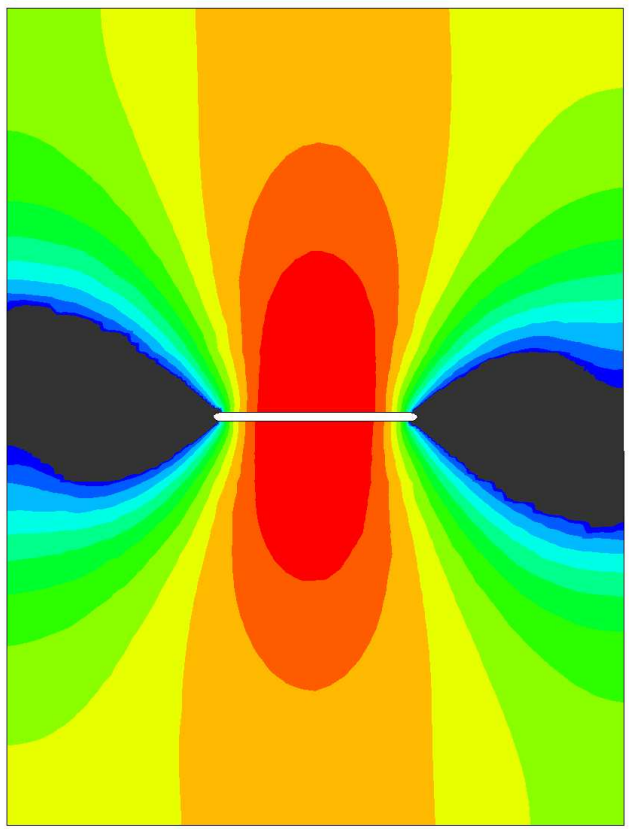

(d) $90^{\circ}$ Layer

Figure 13. Damage zone reaches the edge of the panel in the axial layers, $P=510 \mathrm{KN}$. 


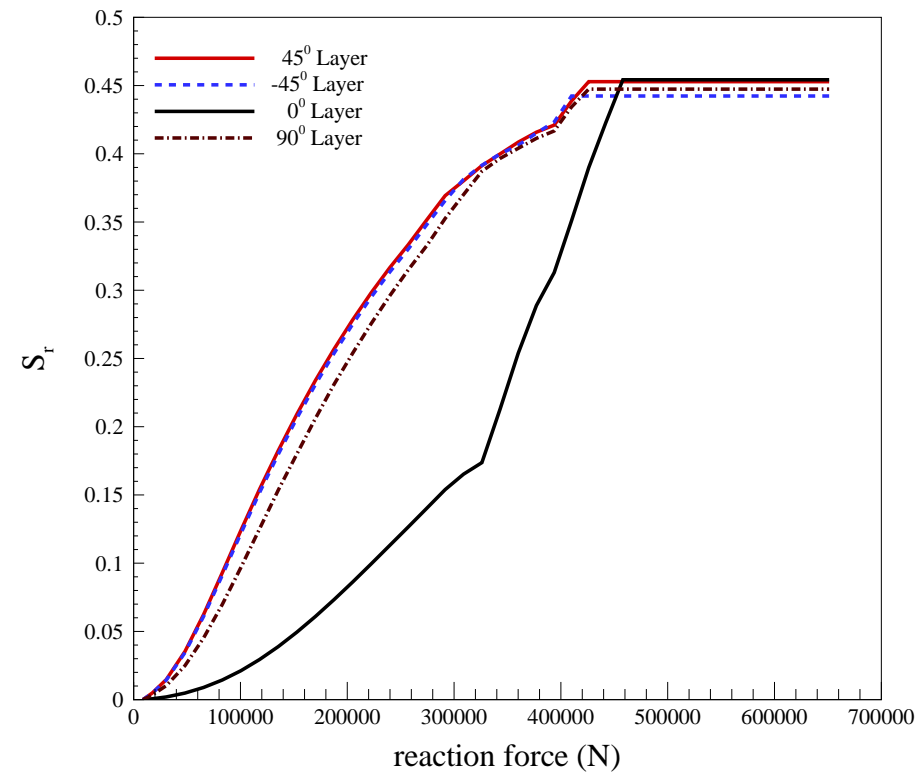

Figure 14. Rate of damage growth near the notch, looking through the thickness. 


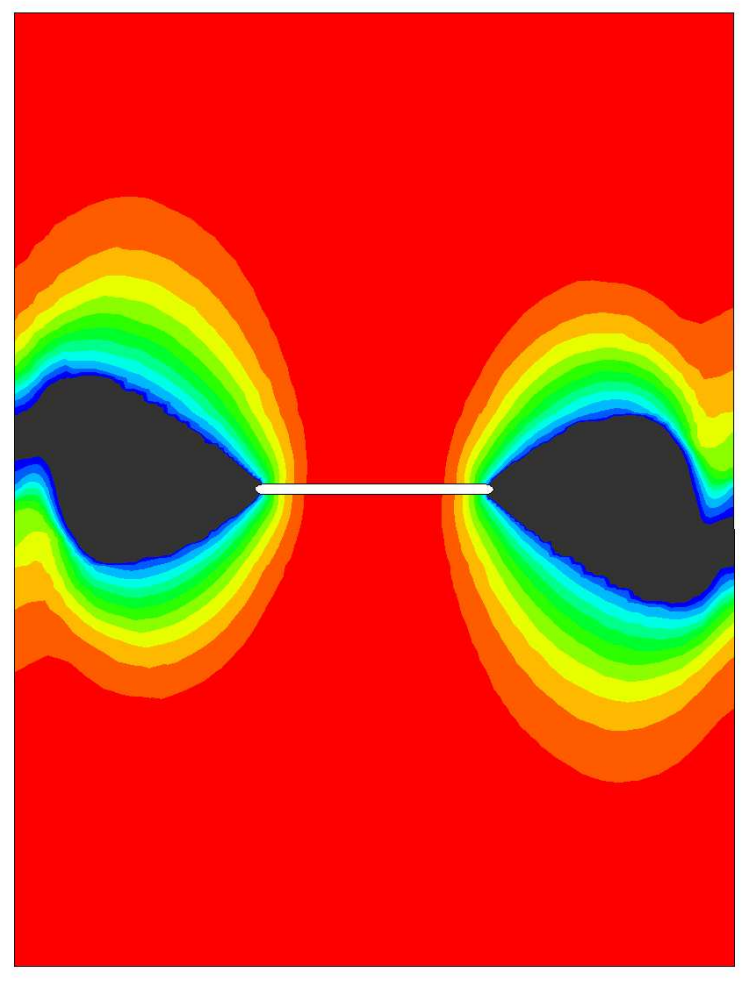

(a) Prediction of damage zone advancement

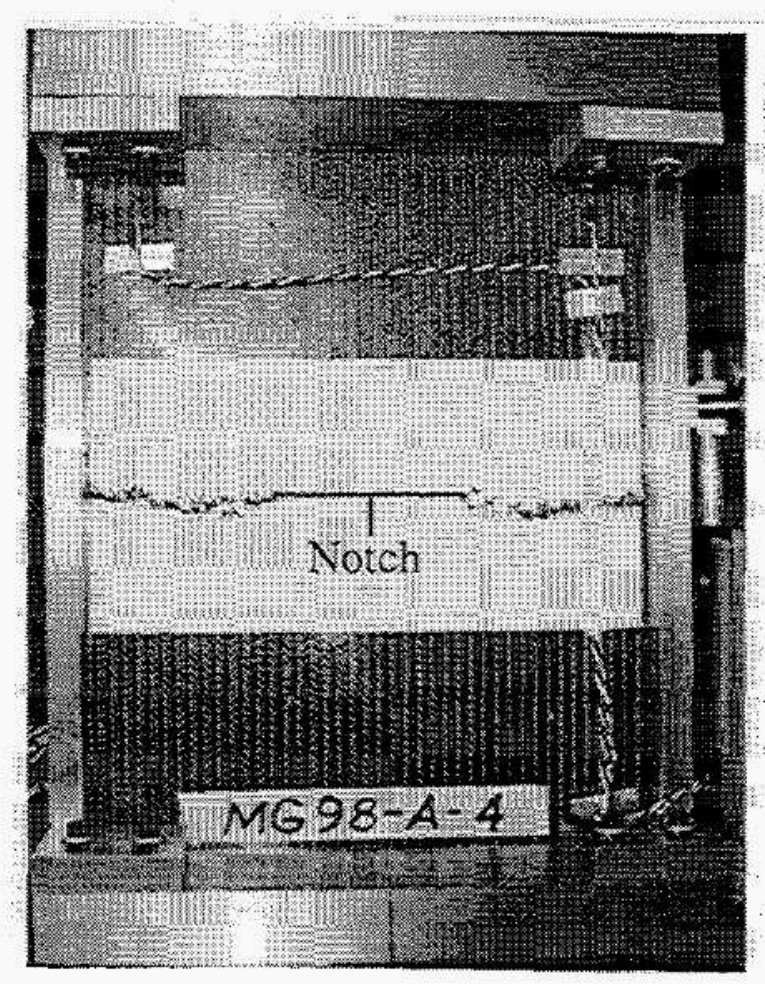

(b) Damage zone date from test ${ }^{9}$

Figure 15. Damage zone growth compared in the FE prediction with the test observation. 


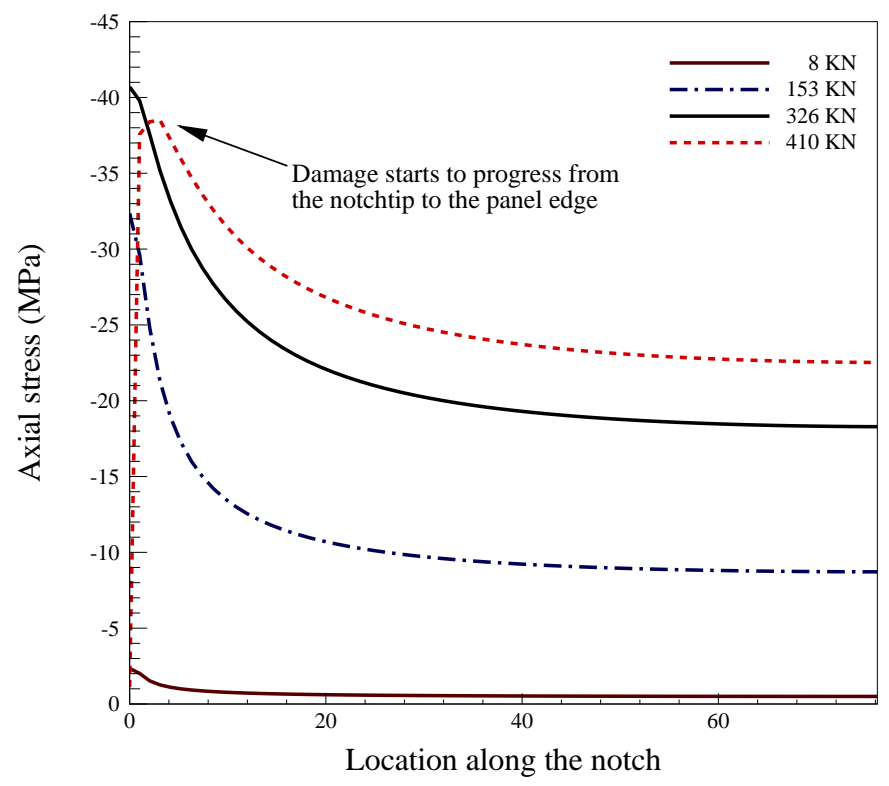

(a)

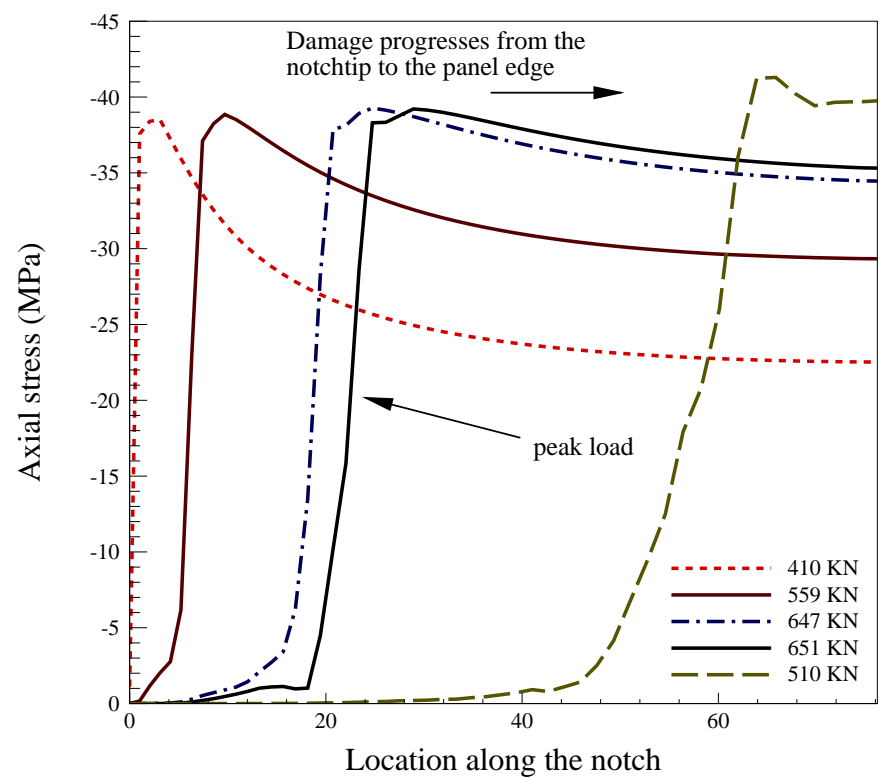

(b)

Figure 16. Evolution of axial stress ahead of the notch tip with external loading for the P90 panel. 


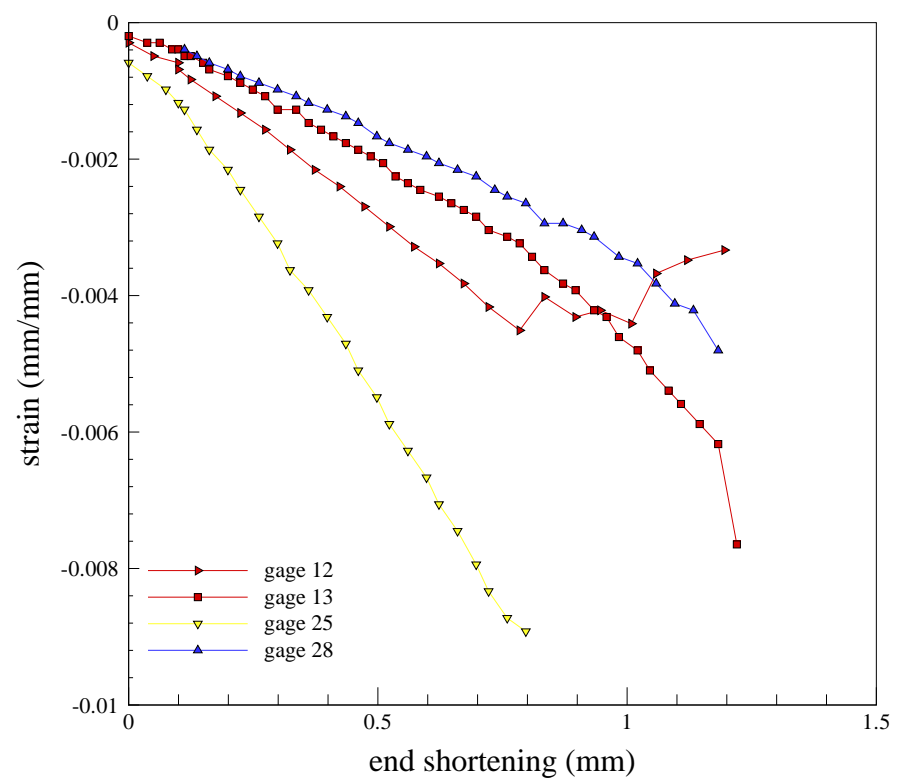

(a) Test measurements

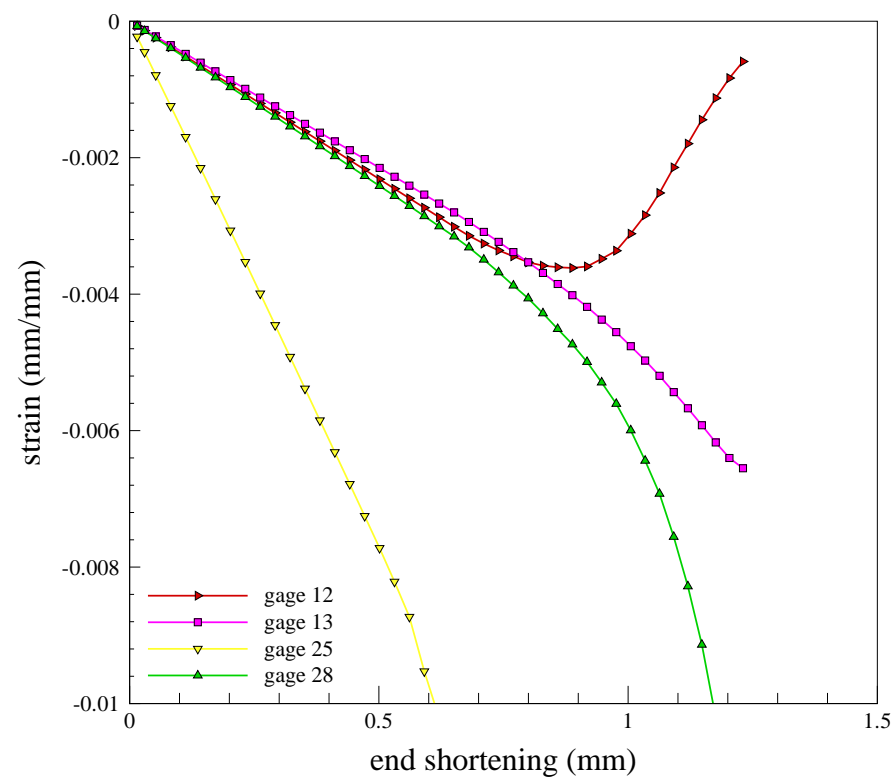

(b) FE predictions

Figure 17. Comparison of axial strains for the P90 panel. 


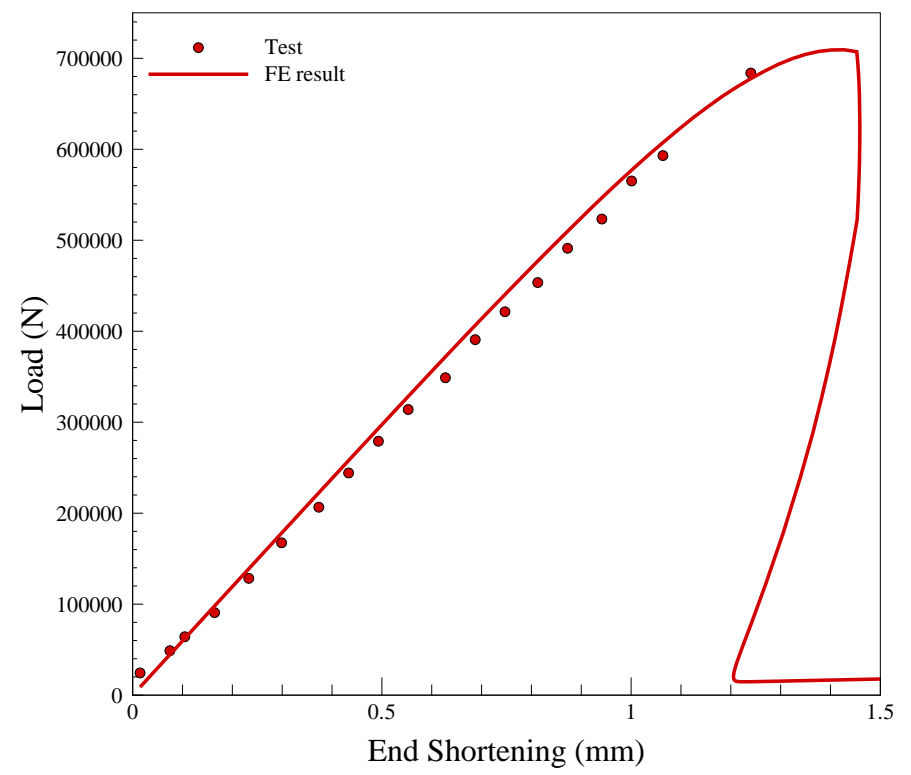

Figure 18. P- $\Delta$ response the $\mathrm{P} 60$ panel.

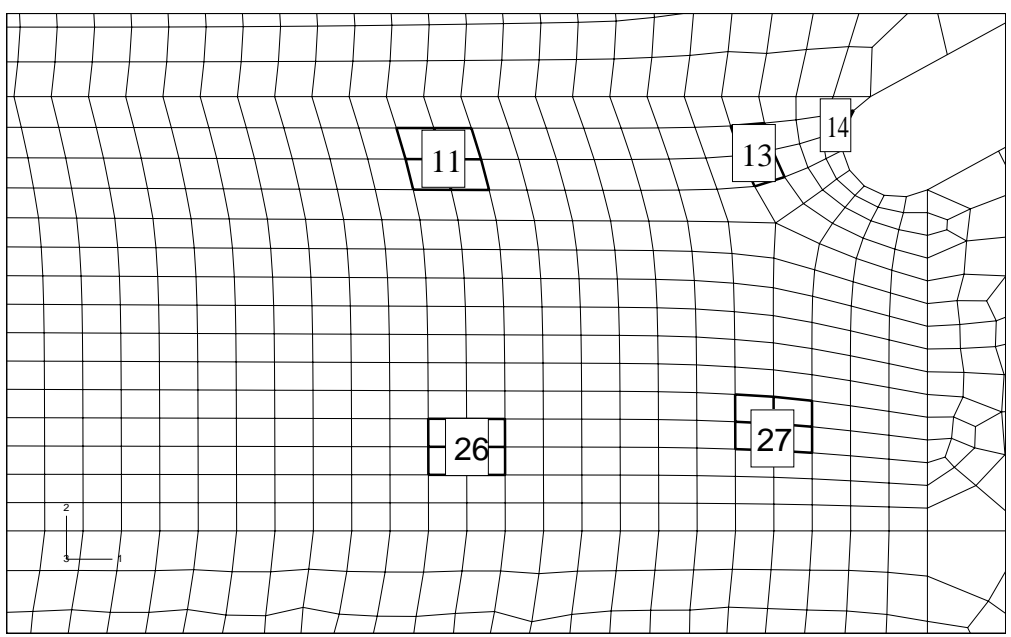

Figure 19. Locations of strain gages on the P60 FE mesh. P45 mesh uses same locations. 


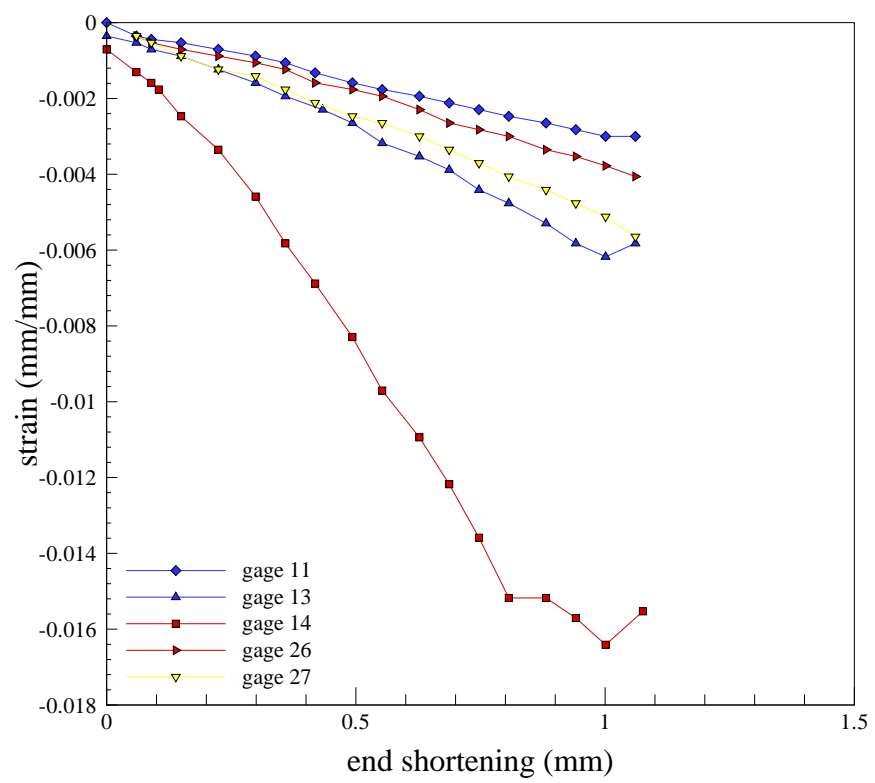

(a) Test measurements

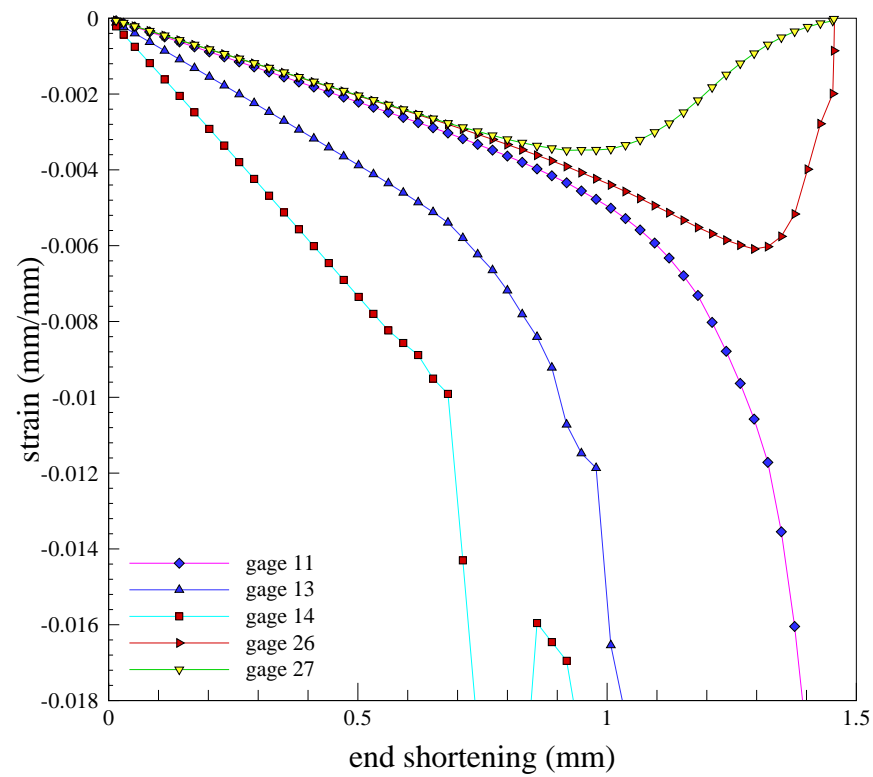

(b) FE predictions

Figure 20. Comparison of axial strains for the P60 panel. 


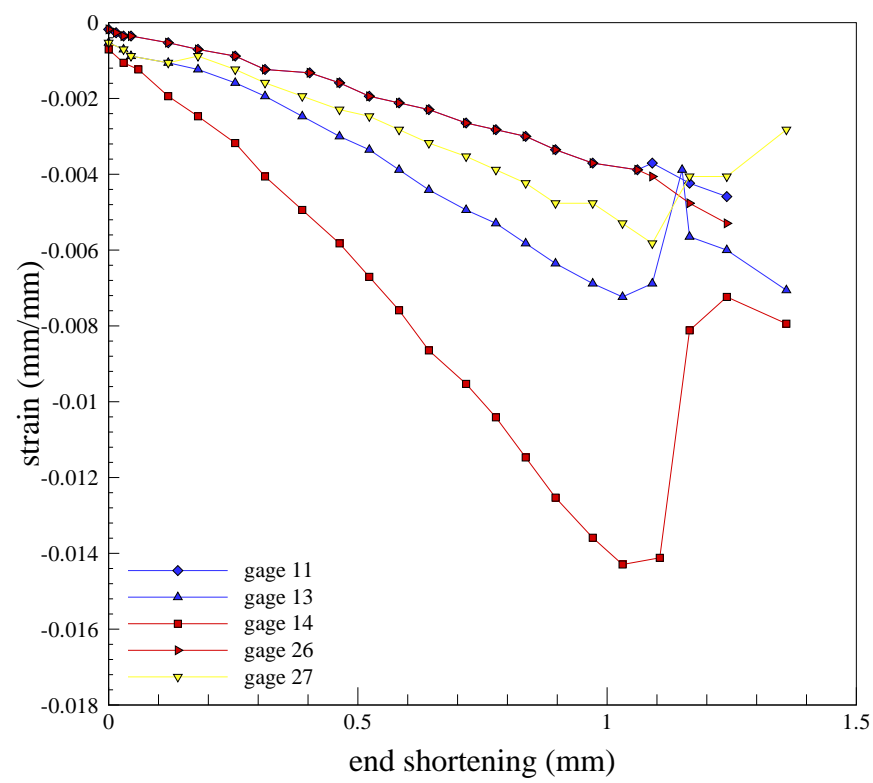

(a) Test measurements

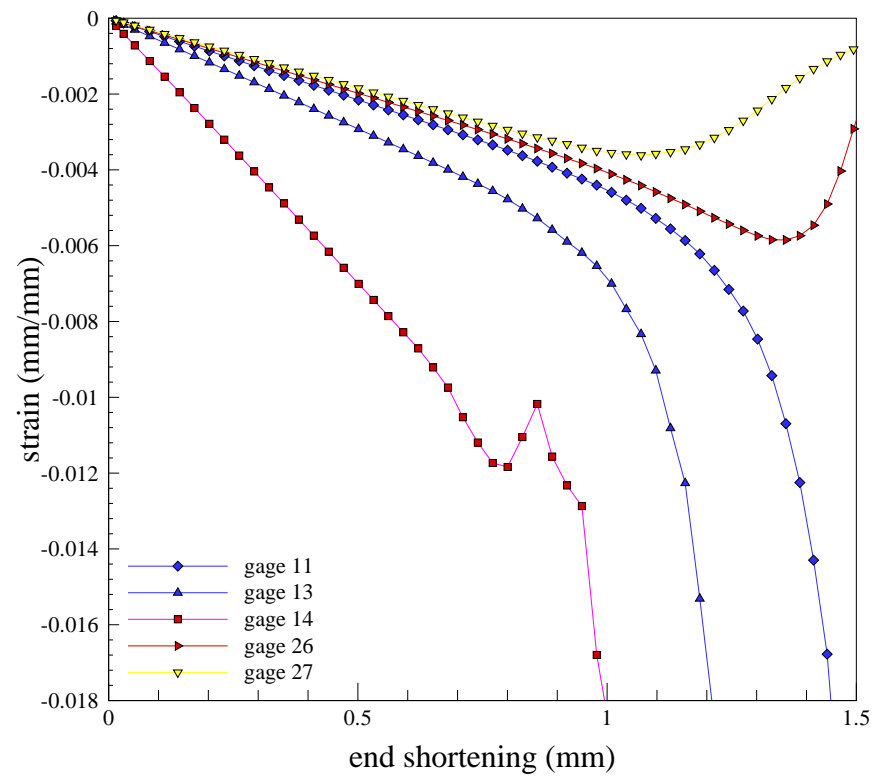

(b) FE predictions

Figure 21. Comparison of axial strains for the P45 panel. 